\title{
Dendrites of Mammalian Neurons Contain Specialized P- Body-Like Structures That Respond to Neuronal Activation
}

\author{
Nicolas Cougot, ${ }^{1 \star}$ Suvendra N. Bhattacharyya, ${ }^{2 \star}$ Lucie Tapia-Arancibia, ${ }^{3,4}$ Remy Bordonné, ${ }^{1}$ Witold Filipowicz, ${ }^{2}$ \\ Edouard Bertrand, ${ }^{1}$ and Florence Rage ${ }^{1}$ \\ ${ }^{1}$ Institut de Génétique moléculaire de Montpellier, Centre National de la Recherche Scientifique Unité Mixte de Recherche 5535-IFR 122, 34000 Montpellier, \\ France, ${ }^{2}$ Friedrich Miescher Institute for Biomedical Research, 4002 Basel, Switzerland, ${ }^{3}$ INSERM U710, Université de Montpellier 2, Montpellier, F-34095 \\ France, and ${ }^{4}$ Ecole de Hautes Etudes Pratiques, Paris, F-75007 France
}

Intracellular mRNA transport and local translation play a key role in neuronal physiology. Translationally repressed mRNAs are transported as a part of ribonucleoprotein (RNP) particles to distant dendritic sites, but the properties of different RNP particles and mechanisms of their repression and transport remain largely unknown. Here, we describe a new class of RNP-particles, the dendritic P-bodylike structures (dlPbodies), which are present in the soma and dendrites of mammalian neurons and have both similarities and differences to P-bodies of non-neuronal cells. These structures stain positively for a number of P-body and microRNP components, a microRNA-repressed mRNA and some translational repressors. They appear more heterogeneous than P-bodies of HeLa cells, and they rarely contain the exonuclease Xrn1 but are positive for rRNA. These particles show motorized movements along dendrites and relocalize to distant sites in response to synaptic activation. Furthermore, Dcpla is stably associated with dlP-bodies in unstimulated cells, but exchanges rapidly on neuronal activation, concomitantly with the loss of Ago2 from dlP-bodies. Thus, dlP-bodies may regulate local translation by storing repressed mRNPs in unstimulated cells, and releasing them on synaptic activation.

Key words: miRNA; P-body; RNA-granule; neurons; dendritic mRNA trafficking; localization

\section{Introduction}

In neurons, local mRNA translation is important to ensure the compartmentalized protein expression required for synaptic plasticity (Klann and Dever, 2004; Fuchs et al., 2006; Sutton and Schuman, 2006; Twiss and van Minnen, 2006). Messenger RNAs are trafficked to dendritic translation sites as parts of ribonucleoprotein complexes, which remain translationally dormant until they reach their destination (Krichevsky and Kosik, 2001; Kindler et al., 2005). Several studies have shown that RNA and RNAbinding proteins undergo motorized transport along axons and dendrites. Interestingly, this frequently involves the formation of large molecular complexes, which are visible microscopically as

\footnotetext{
Received Sept. 1, 2008; revised 0ct. 14, 2008; accepted 0ct. 24, 2008.

This work was supported by grants from Agence Nationale de la Recherche, France (ANR-05-BLAN-0118-01) and La Ligue contre le Cancer. Research by S.N.B. and W.F. was partially supported by EC FP6 Program "Sirocco." Friedrich Miescher Institute is a part of Novartis Research Foundation. S.N.B. is a former recipient of an International Human Frontier Science Program organization (HFSPO) long-term fellowship and is currently holding an HFSPO Career Development Award at Indian Institute of Chemical Biology (IICB). N.C. has a fellowship from L'Association pour la Recherche contre le Cancer. We thank Montpellier RIO Imaging for their assistance. We thank A. Matus and H. Brinkhaus of the Friedrich Miescher Institute for providing us with-cultured rat hippocampal neurons. We also thank T. Hobman, R. Pillai, C. Artus-Revel, J. Lykke-Andersen, R. Willemsen, B. Séraphin, M. J. Fritzler, J. Steitz, and R. Singer for providing plasmids and/or antibodies, Michel Vignes for glutamatergic agonist and antagonist, and $\mathrm{M}$. Kiebler for valuable discussion.

${ }^{*}$ N.C. and S.N.B. contributed equally to this work.

Correspondence should be addressed to Florence Rage, Institut de Génétique moléculaire de Montpellier, 1919 route de Mende 34000 Montpellier, France. E-mail: florence.rage@igmm.cnrs.fr.

S. N. Bhattacharyya's present address: Indian Institute of Chemical Biology, 4, Raja SC Mullick Road, Kolkata 700032, India.

DOI:10.1523/JNEUROSCI.4155-08.2008

Copyright $\odot 2008$ Society for Neuroscience $\quad$ 0270-6474/08/2813793-12\$15.00/0
}

granules (Hirokawa, 2006; Kiebler and Bassell, 2006). For instance, a zipcode binding protein, ZBP1 (IMP1), which binds $\beta$-actin mRNA (Ross et al., 1997), is part of motile granules in dendrites of hippocampal neurons (Zhang et al., 2001) and in Xenopus growth cones (Deshler et al., 1998; Havin et al., 1998). Similarly, survival of motor neuron (SMN) and fragile mental retardation proteins (FMRP) localize in foci that show motorized movement along dendrites (Zalfa et al., 2006).

MicroRNAs (miRNAs) are a class of $\sim 21$-nt-long, noncoding RNAs that can reversibly repress translation of target mRNAs (Pillai et al., 2007). This property makes them good candidates for factors regulating local mRNA translation. Dozens of different miRNAs have been identified in neuronal vertebrate cells (Sutton and Schuman, 2006), and a brain specific miRNA has recently been shown to accumulate in dendrites and to regulate dendritic spine development by controlling local expression of protein kinase LIMK1 (Lagos-Quintana et al., 2002; Krichevsky et al., 2003; Schratt et al., 2006). Interestingly, components of miRNA machinery such as argonaute (Ago) proteins and miRNAs, and mRNAs repressed by miRNAs are enriched in evolutionary conserved cytoplasmic structures called P-bodies (also termed Dcp or GW bodies), which function as sites of both mRNA degradation (Cougot et al., 2004), and storage of translationally repressed mRNAs (Liu et al., 2005; Pillai et al., 2005; Bhattacharyya et al., 2006). The markers most frequently used to visualize P-bodies are components of the decapping complex, Dcp1a and Dcp2, decapping activators (e.g., RCK/p54), the 5'-3' exonuclease Xrn1, and GW182, which is involved in the miRNA 
pathway. In addition, P-bodies also contain many other factors involved in mRNA metabolism and regulation of translation (Eulalio et al., 2007). A recent study has shown that, in Drosophila, neuronal processes contain structures related to P-bodies. These granules contain dStaufen and dFMRP and share many components with somatic P-bodies (Barbee et al., 2006), raising the possibility that some previously characterized RNA granules represent a specialized class of P-bodies, adapted to neuronal function.

P-bodies in mammalian neurons have not been characterized. It is not known whether they are restricted to the soma, or whether they are also present in dendrites or axons. Furthermore, the relationship between P-bodies and previously described neuronal RNA granules is unknown, and the possibility that neuronal P-bodies could be involved in mRNP transport and storage has not been explored. Here, we demonstrate that P-body-like structures are present in the soma and dendrites of mammalian neurons and have both similarities and differences to P-bodies of non-neuronal cells.

\section{Materials and Methods}

Primary cultures of rat neurons. Primary cultures of rat hypothalamic neurons were prepared by mechano-enzymatic dissociation of fetal Sprague Dawley rat hypothalami (day 17), as described previously (Rage et al., 1999). Briefly, cells were grown during 8-10 d, at which time they reach maturity and make well established and stable synapses (Scarborough et al., 1989). Neuronal cultures from E19 rat hippocampus were prepared and maintained in culture on glass coverslips for 3 weeks according to the methods described previously (Fischer et al., 1998).

Plasmid constructs. Plasmids allowing expression of GFP-Dcpla (van Dijk et al., 2002), YFP-ZBP1 (Eom et al., 2003), GFP-FMRP (Tiruchinapalli et al., 2003), and plasmids encoding Renilla luciferase reporters RL-3xB and RL-3xBMut (Pillai et al., 2005), were previously described. Ago2-GFP and SMN-RFP were constructed with the Gateway cloning strategy (InVitrogen). Details of plasmid construction are available on request.

Transfections. Primary hypothalamic neurons were transfected with calcium phosphate plasmid DNA precipitate, according to the published protocol (Xia et al., 1996). Briefly, cells were placed in a transfection medium containing DMEM, DMKY (0.5\% phenol red, 1 м HEPES, 10 $\mathrm{mM} \mathrm{MgCl}_{2}$ ), received the preformed calcium phosphate plasmid DNA precipitate, and were incubated for $45 \mathrm{~min}$. The medium was then removed and cells were washed with HBS for 1 min. Preconditioned medium, removed from the culture before the transfection, was reintroduced and cells were continued in culture for 24 additional hours. For hypothalamic neurons, $2-3 \mu \mathrm{g}$ of plasmid DNA were used per 35 $\mathrm{mm}$ dishes.

HeLa cells were transfected using Lipofectamine Plus reagent or Lipofectamine 2000 (Invitrogen) according to manufacturer's protocol. 100$200 \mathrm{ng}$ of plasmid DNA per well of a 6 well tissue culture plate was used for each transfection and cells were analyzed $48 \mathrm{~h}$ after transfection.

For drug treatment, hypothalamic neurons were cultivated for $8 \mathrm{~d}$ in vitro, and cells were incubated with different glutamatergic receptor agonists [NMDA $(30 \mu \mathrm{M})$, kainate $(50 \mu \mathrm{M})$ or DHPG $(50 \mu \mathrm{M})]$, or BDNF $(50$ $\mathrm{mg} / \mathrm{ml}$ ) and $\mathrm{KCl}(50 \mathrm{~mm})$ for $15 \mathrm{~min}, 30 \mathrm{~min}$ or $1 \mathrm{~h}$. When indicated, specific antagonists of NMDA and kainate, MK801 $(10 \mu \mathrm{M})$ and DNQX $(50 \mu \mathrm{M})$, respectively, were added to the culture medium $10 \mathrm{~min}$ before agonist treatment.

Immunofluorescence and in situ hybridization. For immunofluorescence analysis, neurons were fixed with prewarmed $4 \%$ paraformaldehyde and 3\% sucrose in PBS for $10 \mathrm{~min}$ at room temperature. Cells were permeabilized in $0.2 \%$ Triton X-100 in $1 \times$ PBS for 10 min and blocked in PBS containing 1\% BSA and 5\% normal goat serum for $1 \mathrm{~h}$ at room temperature. Neurons were incubated with the primary antibodies in the blocking buffer at $4^{\circ} \mathrm{C}$ overnight. Secondary antibodies were labeled with Alexa 488 or Alexa 594 and were used at 1:500 dilution. Rabbit polyclonal anti-Dcp 1 serum (kindly provided by B. Séraphin, CNRS, Gif-surYvette), raised against a recombinant human Dcpla, was used at 1:4000 dilution. Mouse monoclonal anti-Dcpla was purchased from Abcam. Goat anti-PSD95 antibody (Santa Cruz), and rabbit anti-Ago2 (a kind gift from T. Hobman, University of Alberta, Edmonton, Alberta, Canada), raised against a recombinant rat Ago2 protein fragment, were used at 1:100 dilution. Note that anti-Ago2 antibody detects all four mammalian Ago proteins. Rabbit anti-RCK/p54 (Bethyl Laboratory), anti-rRNA monoclonal Y10B (obtained from J. Steitz, Yale University Medical School, New Haven, CT), and anti-ZBP1 antibodies (obtained from the laboratory of R. H. Singer, Albert Einstein College of Medicine, NY) were used in 1:500 dilutions. The autoimmune serum against human GW182 protein (18033; a gift from M. J. Fritzler, University of Calgary, Calgary, Alberta, Canada) was used for detection of GW182. Anti-TAU1 antibody was a kind gift from V. Homburger, IGF, Montpellier, France.

For in situ analysis of neurons, slide preparation, hybridization and washing were done as described previously (Pillai et al., 2005). The miRCURY LNA probe used for the in situ detection of miR-128 or let-7 miRNA were purchased from Exiqon (Vedbaek, Denmark) and labeled with digoxigenin, using the terminal transferase 3 '-DIG-tailing kit (Roche Biochemicals). The anti GW182 serum was used as the source of primary antibody against GW182 to stain the P-body-like structures. Alexa 488 fluorochrome labeled goat-anti human antibody (1:500; to detect the GW182 signal) was used in combination with the Fluorescent Antibody Enhancer Set for DIG Detection (Roche Biochemicals) to detect the signals for the miRNAs.

Preparation of synaptoneurosomes, immunoprecipitation, and Western and Northern blot analyses. Synaptosomes from brain extracts of adult male BALB/C6 mice were prepared essentially as described previously (Bagni et al., 2000). A brain homogenate was prepared in a homogenization buffer [20 mm HEPES-KOH pH 7.5, containing $320 \mathrm{~mm}$ sucrose, $0.25 \mathrm{~mm}$ EDTA, $30 \mathrm{U} / \mathrm{ml}$ Rnasin and $1 \times$ protease inhibitor mix without EDTA (Roche)]. The homogenate was precleared by centrifugation at $1000 \times g$ and then centrifuged at $14,000 \times g$ to collect crude synaptosomes. The pellet was resuspended in the homogenization buffer and further purified on a Percoll step gradient (2, 6, 10 and 20\% Percoll concentration), and by flotation on a discontinuous Optiprep gradient $(9,12.5,15,25$ and $35 \%)$, all prepared in the homogenization buffer. The purified synaptosome fraction was stored at $-70^{\circ} \mathrm{C}$ in the homogenization buffer containing $50 \%$ glycerol. For protein analysis, synaptosomes were extracted with an equal volume of $2 \times$ IP buffer $(20 \mathrm{~mm}$ Tris- $\mathrm{HCl}$, $\mathrm{pH} 7.5,10 \mathrm{~mm} \mathrm{MgCl}_{2}, 400 \mathrm{~mm} \mathrm{KCl}$, and 1\% Triton X-100) for $15 \mathrm{~min}$ on ice. The extract was clarified by centrifugation at $14,000 \times g$ for $5 \mathrm{~min}$ at $4^{\circ} \mathrm{C}$ and the supernatant used for immunoprecipitation analysis. AntiRCK/p54 and anti-ZBP1 antibodies, described above, were cross-linked to Protein G Sepharose beads and $25 \mu \mathrm{l}$ of cross-linked beads (500 ng of proteins) were incubated with a supernatant prepared from $1 \mathrm{mg}$ of purified synaptosomes, in $1 \mathrm{ml}$ reaction at $4^{\circ} \mathrm{C}$ overnight. After washing, the beads were extracted with SDS-sample buffer and analyzed on a $10 \%$ SDS-PAGE followed by Western blotting, using anti-ZBP1 (1:1000) and anti-RCK/p54 (1:10,000) antibodies.

For Western analysis, $100 \mu \mathrm{g}$ of total protein from each synaptosome purification step was resolved on 10\% SDS-PAGE, followed by Western blotting using anti-Ago2 (1:1000) and anti-PSD95 (1:500) antibodies. For Northern blot analysis, $10 \mu \mathrm{g}$ of total RNA extracted from each fraction was resolved on 15\% $7 \mathrm{~m}$ urea-PAGE, electrotransferred to $\mathrm{Ny}$ bond $\mathrm{N}^{+}$membrane, and hybridized with ${ }^{32} \mathrm{P}$-labeled oligodeoxynucleotide complementary to miR-128.

Live cell imaging. For live cell analysis, we used a wide-field Nikon TE200 (100× objective, NA 1.45), equipped with an EM-CCD camera (Cascade 512B, Roper). For FRAP, z-stacks were captured every $3 \mathrm{~s}$ with a piezzo motor. For image analysis, fluorescence intensities were measured as described by Boireau et al. (2007). Briefly, a small parallelepiped $(1 \times 1 \times 1.5 \mu \mathrm{m})$ was placed at the most intense area of the region in which the foci resided. This operation was done automatically by a macro that was created in ImageJ. This automatic tracking of foci in three dimensions (3D) allowed to correct cell movements and to minimize signal from diffusing proteins. The vailidity of the tracking procedure was verified by eye. Signal was then substracted from background and normalized to prebleached values. For time-lapse, z-stacks were captured every 
200-250 ms during 5-10 s. Movies were then assembled after projection of z-stacks using MetaMorph.

Image acquisition and processing. Images were acquired on a DMRA microscope equipped for epifluorescence, and with a $100 \times$ PlanApo objective and a 1.6 $\times$ eyepiece. Digital images were recorded with a 12-bit C4795-NR CCD camera (Hamamatsu). Both the camera and the microscope were controlled by the software MetaMorph. Three-dimensional images were deconvolved with the software Huygens 2.3 (Scientific Volume Imaging b.v.), using a MLE algorithm. Maximal image projections of the resulting stacks were then converted to 8-bit images and colorized with PhotoShop (Adobe).

Pictures representing neurons over long distances were reconstructed from three pictures taken with $100 \times$ objective and assembled with MRI Cell Image Analyzer (Volker Bäcker). To define the border of neurons, we used the weak and diffuse cellular autofluorescence in immunofluorescence experiments, and the diffuse GFP signal in transfected cells. Distances of different granules along the dendrites were measured using NeuronJ software (http://www.mri.cnrs.fr/index.php?m=38) (Meijering et al., 2004). For experiments done in Friedrich Miescher institute, images were taken with a Zeiss Imager Z1 microscope equipped with Zeiss Plan-APOCHromat $100 \times$ or $40 \times$ lens and AxioCam MRM T2C1.0X monochrome camera. For taking DIC images, a filter adapter PA HC 100X/1.40 II was used. The images were processed either with AxioVision Rel.4.5 or Imaris software, and mounted in Adobe Photoshop CS2.

For the quantitative analysis of the colocalization of foci labeled by the different proteins, we used the Spot function of Imaris (Bitplane), which allowed us to consider only the signal present in foci. This software first applies a Gaussian filter of a given size $(0.3 \mu \mathrm{m}$ in this case) to remove small objects, and then identifies local maxima above a given threshlod (the same threshold was used all images of a given data set). Eyeexamination verified that this procedure correctly identified dlP-bodies and other foci present in cells. To quantify colocalization between foci, the Spot function was run in each channel, and the spots that colocalized or did not colocalize were then counted. Although the numbers calculated were similar to those found by eye-examination, this ensured an unbiaised analysis of the images. Each colocalization analysis was performed on a total of $6-10$ cells representing $60-125$ spots. Concerning Xrn1, we compared the localization of Dcpla foci that had a similar intensity in the soma and dendrites. This ensured that the lack of detection of Xrn1 in dendritic P-bodies was not caused by a low intensity of the signals.

\section{Results}

\section{P-body components are enriched in dendritic foci in rat} hippocampal and hypothalamic neurons

Localization of selected P-body components, Dcpla, GW182, RCK/ p54, and Ago proteins, was analyzed in primary cultures of rat hippocampal and hypothalamic neurons. In hippocampal neurons labeled with anti-GW182 antibodies, the signal was concentrated in foci (Fig. 1A), and double-labeling experiments with anti-Dcpla, anti-RCK/p54 and anti-Ago2, revealed that most of the GW182 foci contain these proteins (supplemental Figs. S1, S2, and S3, available at www.jneurosci.org as supplemental material). However, not all foci were doubly labeled, indicating that their composition tolerated some heterogeneity. Likewise, in hypothalamic neurons labeled with anti-Dcpla antibodies, the signal appeared in foci, and many of them were also labeled with anti-Ago2 and anti-RCK/p54 antibodies (Fig. 1B,D). Again, the foci did not match perfectly, and in particular, a fraction of Ago2 foci did not contain Dcp1a. To quantify the degree of colocalization between these proteins, we used first Dcpla as a reference and counted the number of Dcpla foci that contained GW182, Ago2 or RCK/p54. We then performed the reciprocal analysis by using foci labeled by GW182, Ago2 or RCK/p54 as references, and counting the fraction that contained Dcpla. The results, shown in supplemental Figure S4 (available at www.jneurosci.org as supplemental material), showed that Dcpla, GW182 and RCK/p54 all colocalized together with a high frequency $(>65 \%)$. Dcpla foci also contained Ago2 nearly all the time, but Ago2 frequently formed additional foci that did not contained detectable Dcpla (60\% of Ago2 foci).

To determine whether the foci were in dendrites, axons, or both, we labeled hypothalamic neurons for Dcpla and either MAP2, a dendritic marker, or TAU1, an axonal protein. Dcp1a foci were present in dendrites (Fig. 1C), but appeared excluded from axons (supplemental Fig. S5A, available at www.jneurosci. org as supplemental material). Next, we assessed whether the foci were present in postsynaptic compartments. In hippocampal neurons, costaining for the postsynaptic density protein PSD95 revealed that a small fraction of GW182 foci accumulated in the vicinity of dendritic spines (Fig. $1 A$ ), and this was further supported by colabeling with TRITC-phalloïdin, which stains the polymerized actin in dendritic spine heads (supplemental Fig. S5B, available at www.jneurosci.org as supplemental material). Synaptic localization of some P-body components was also confirmed by a biochemical approach. Purified synaptoneurosomes, enriched in postsynaptic density protein marker PSD95, were found to contain Dcpla (Fig. 1E).

Thus, our results indicate that in hippocampal and hypothalamic neurons, P-body-like structures are present in dendrites, sometimes in proximity of synapses. These structures contain Dcp1a, GW182, RCK/p54 and Ago2, but they appear to have some degree of heterogeneity as the foci labeled by these proteins did not perfectly overlap. Because the vast majority of the foci labeled by anti-Dcpla or anti-GW182 antibodies colocalized with each other, we choosed to use GW182 and Dcp1a as references in the subsequent series of experiments, and we referred to the structures they label as dlP-bodies (dendritic P-body-like structures).

\section{Neuronal dlP-bodies contain miRNAs and a repressed mRNA target}

Because dlP-bodies were found to contain Ago2, a component of miRNPs, we also assessed the localization of miRNAs. Let-7 miRNA is highly expressed in brain, and in situ hybridization indicated that it was present in dlP-bodies as indicated by its colocalization with GW182 (Fig. 2A). The mutant let-7 probe (Pillai et al., 2005), used as a control, did not stain the GW 182 foci (supplemental Fig. S6A, available at www.jneurosci.org as supplemental material). Another miRNA, miR-128, known to be specifically expressed in neurons (Smirnova et al., 2005), was likewise present in dlP-bodies (Fig. $2 \mathrm{~B}$ ) and also found to be enriched in purified synaptosomes (supplemental Fig. S6B, available at www.jneurosci.org as supplemental material). However, it should be noted that in situ hybridization also revealed the presence of miRNAs in some foci not overlapping with this P-body marker (Fig. 2A,B), similar to the case of Ago2 (see above).

To find out whether mRNAs repressed by miRNAs were also targeted to dlP-bodies, hypothalamic neurons were transfected with a plasmid expressing a Renilla luciferase (RL) reporter mRNA designed to be translationally repressed by let-7 miRNA, and known to accumulate in P-bodies in HeLa cells (RL-3xB) (Pillai et al., 2005). This mRNA, but not the control reporter mRNA containing mutated let-7 sites, showed colocalization with CFP-Ago2 foci in dendrites, consistent with its enrichment in dlPbodies (Fig. 2C; supplemental Fig. S6C, available at www. jneurosci.org as supplemental material). We have obtained similar results with Dcpla (data not shown). Thus, similar to the situation observed in somatic cells, dlP-bodies contain miRNAs and mRNAs undergoing miRNA-mediated repression. 


\section{Relationship between dlP-bodies and other RNA granules}

Numerous proteins involved in mRNA metabolism were shown to localize to different types of granules in dendrites of neuronal cells (see Introduction), but little is known about how these granules relate to each other and to dlP-bodies. Thus, we compared the localization of three proteins that have been observed to form granules in dendrites, ZBP1, FMRP, and SMN, with the localization of either of Dcpla or GW182. Their localization in dendrites was further compared with that of the neuronal cell body and HeLa cells.

Antibodies against ZBP1 labeled foci in dendrites of hippocampal and hypothalamic neurons, and a significant fraction of them was stained by antibodies against GW182 or Dcpla (Fig. 3A and data not shown). The frequency at which ZBP1 was present in dlP-bodies was measured with fluorescent proteins expressed in hypothalamic neurons, using Dcpla as a reference. We found that $90 \%( \pm 8 \%)$ and $70 \%$ $( \pm 5 \%)$ of CFP-Dcpla foci contained YFPZBP1 in dendrites and soma, respectively. However, similar to the case of Ago2, YFPZBP1 was often forming dendritic foci that did not contain detectable Dcpla (supplemental Fig. S4, available at www.jneurosci. org as supplemental material). Interestingly, in HeLa cells, only $24 \%( \pm 6 \%)$ of CFP-Dcpla foci were positive for YFPZBP1 (supplemental Fig. S7, available at www.jneurosci.org as supplemental material). Association between ZBP1 and P-body components in neuronal cells was also tested by coimmunoprecipitation experiments, using synaptoneurosomal preparations and antibodies against ZBP1 and RCK/p54 (Fig. 3E). The anti-ZBP1 antibody coimmunoprecipitated RCK/p54 whereas the anti-RCK/p54 immunoprecipitated material was positive for ZBP1, indicating that the colocalization reflected a physical association, either direct or indirect.

We were unable to obtain reliable labeling with anti-SMN and anti-FMRP antibodies in hypothalamic or hippocampal neurons, and we thus used plasmids expressing fluorescently tagged proteins and labeled dlP-bodies with antibodies against Dcpla. Nearly all Dcpla foci contained GFP-FMRP, both in dendrites and soma of hypothalamic neurons (90\%) (Fig. $3 C$; supplemental Fig. S4, available at www.jneurosci.org as supplemental material), and also in HeLa cells $(100 \%$; data not shown). Reciprocally, most GFP-FMRP foci contained Dcpla, indicating that it is also a good marker of dlPbodies. In the case of SMN-RFP expressing neurons, most SMN positive foci did not contain Dcpla ( $75 \%$ of SMN foci).

A

C

D
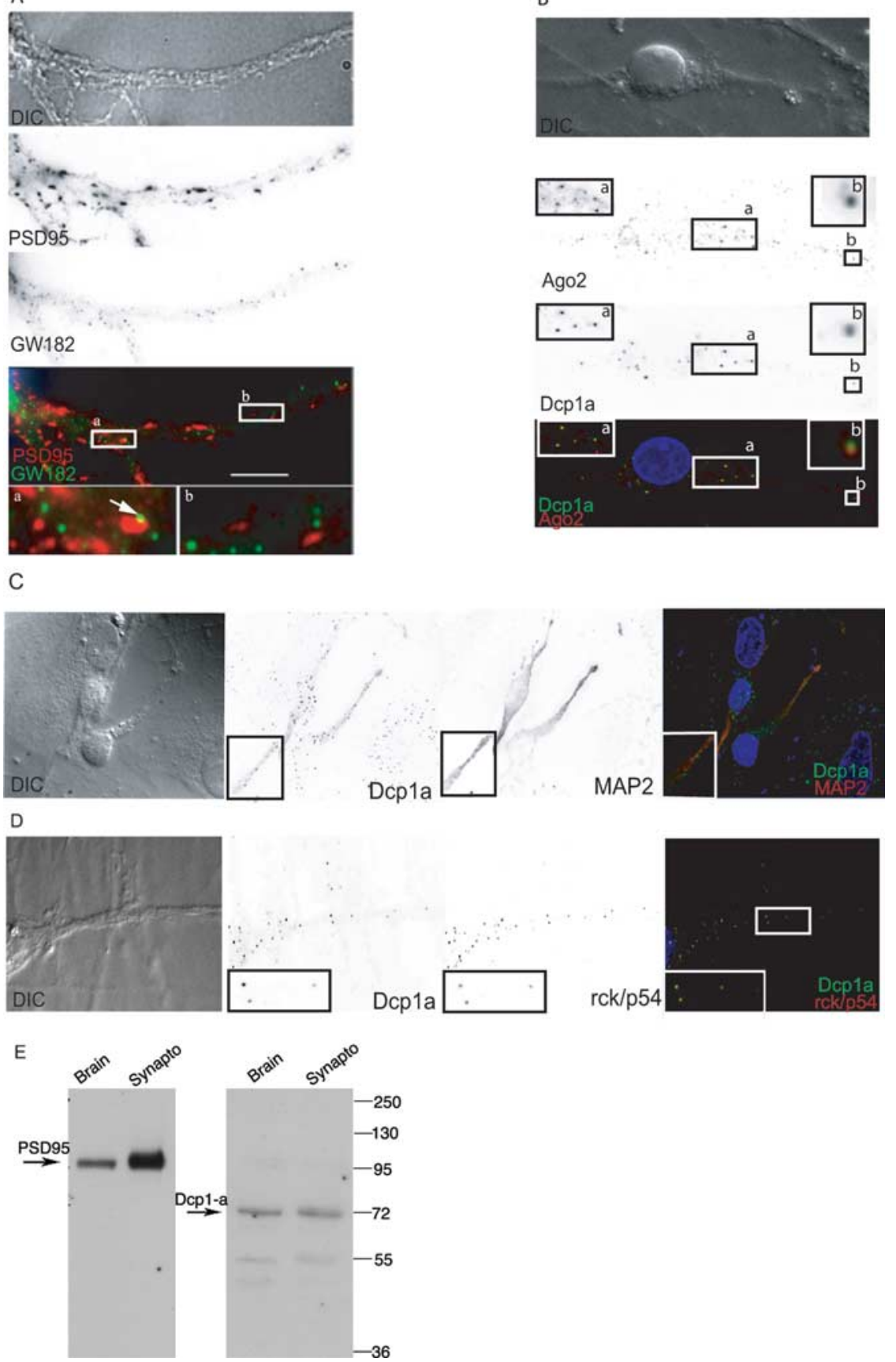

Figure 1. $A-E$, Dendritic localization of P-body-like structures in rat hippocampal and hypothalamic neurons. In vitro cultured rat hypothalamic $(\boldsymbol{B}-\boldsymbol{D})$ or hippocampal $(\boldsymbol{A})$ neurons were used for immunofluorescence analysis to study the distribution of several P-body markers. In $\boldsymbol{A}-\boldsymbol{D}$, scale bars represent $10 \mu \mathrm{m}$. The insets show enlargements of indicated regions $(4 \times)$. $\boldsymbol{A}$, Costaining of hippocampal neurons with anti-GW182 (bottom) and anti-PSD95 (middle; a marker for synapses) antibodies. GW182-positive granule present close to PSD95 positive synaptic site is marked by an arrow. Overlay (colored panel): GW182 staining is in green and PSD95 in red. DIC image of the same dendrite is shown in the top. $\boldsymbol{B}$, Costaining of hypothalamic neurons with anti-Dcpla (top) and anti-Ago2 (middle). Overlay (bottom): Dcpla staining in green, Ago2 in red. C, Foci that are stained with anti-Dcp1a serum (left) were also labeled with anti-RCK/p54 antibodies (middle) in processes of cultured hypothalamic neurons. Overlay (right): Dcp1a is in green and rck/p54 is in red. D, Anti-Dcp1a antibody (left) labels foci in dendrites of rat hypothalamic neurons. Neurons were costained for neuronal dendritic marker MAP2 (middle). On the overlay (right) panel, Dcp 1a is in green and the MAP2 staining is in red. Nuclei are stained with DAPI (in blue). $\boldsymbol{E}$, Western blot reveal the presence of Dcp1a in crude and purified synaptosomal fractions prepared from the mouse brain extract.
B

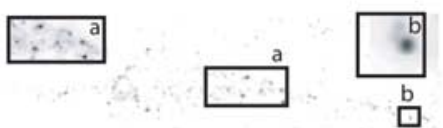

Ago2
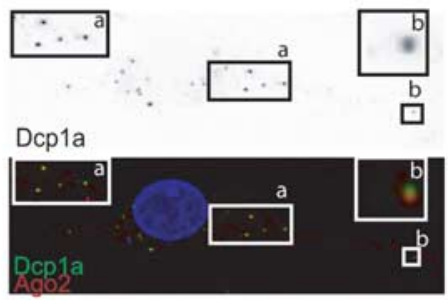

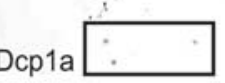

$\mathrm{rck} / \mathrm{p} 54$

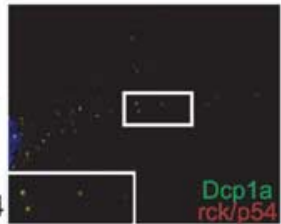

Similarly, the fraction of Dcpla foci that contained SMN was only $30 \%( \pm 10 \%)$ in dendrites and $35 \%( \pm 6 \%)$ in soma (Fig. $3 D$ ), whereas no colocalization was observed in HeLa cells (supplemental Fig. S7, available at www.jneurosci.org as supplemental ma- 


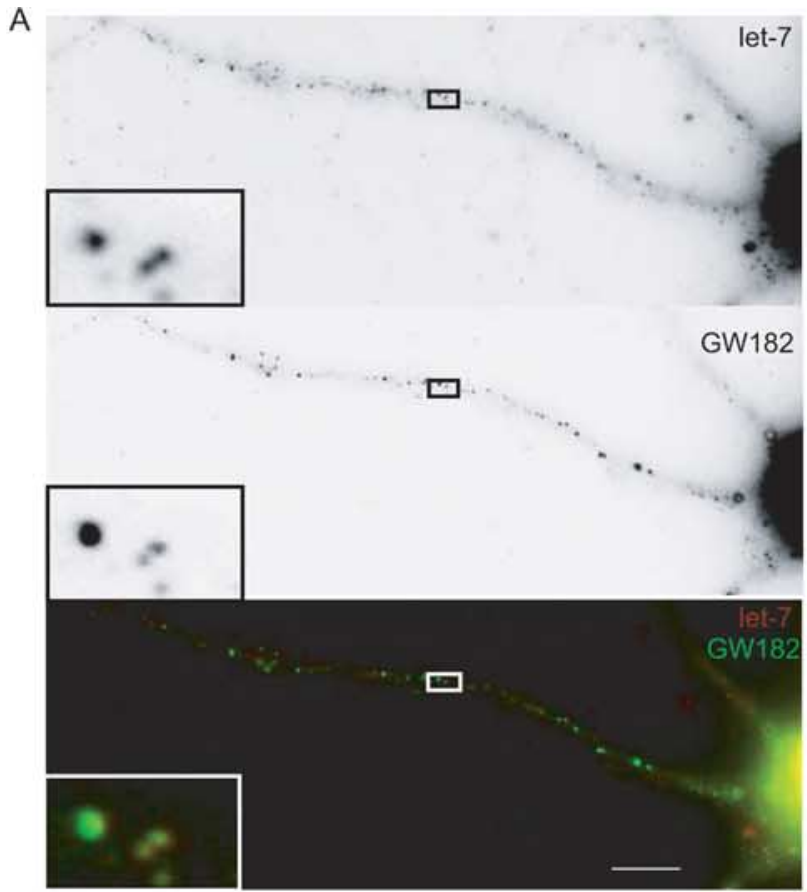

B

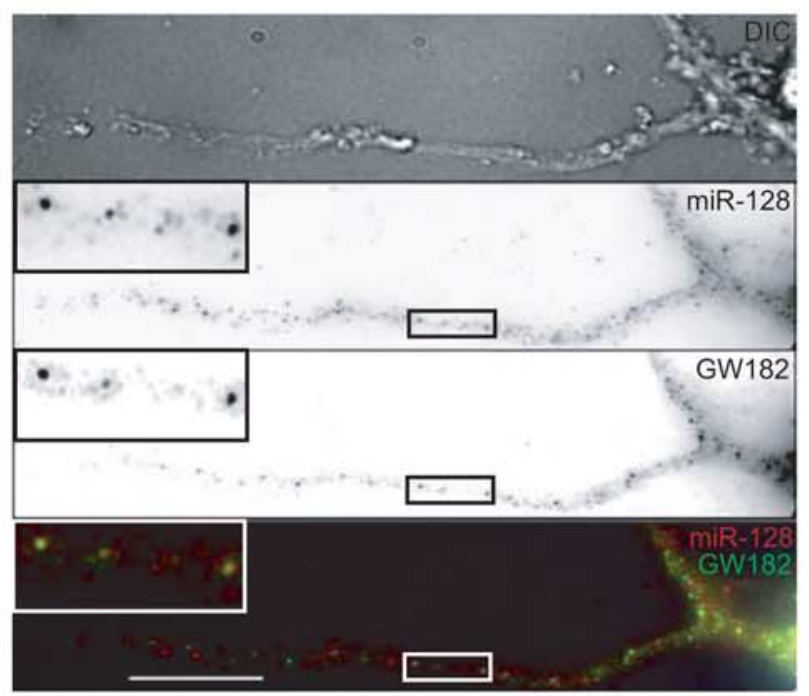

c

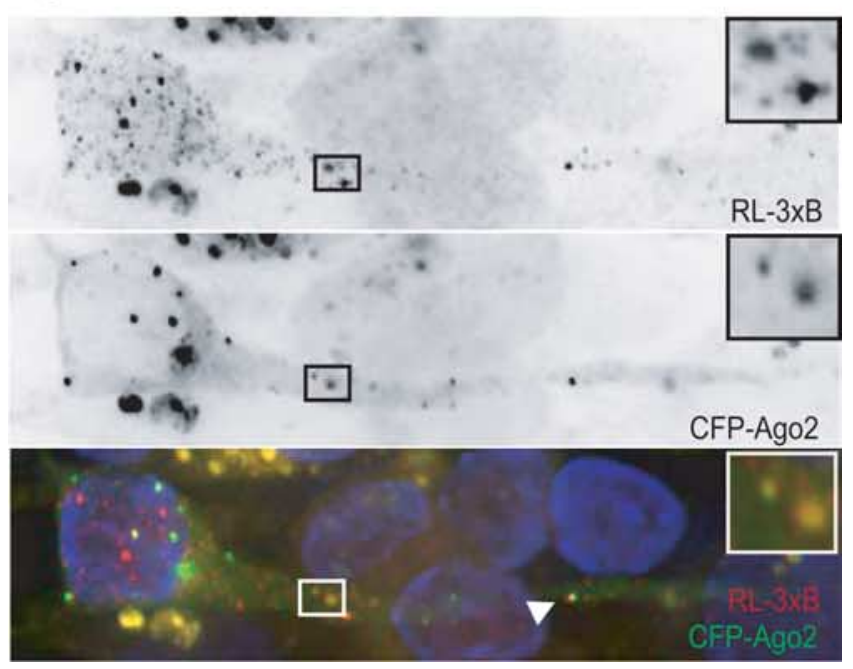

terial). Altogether, these experiments show that dlP-bodies frequently contain ZBP1 and FMRP, and rarely SMN.

Xrn 1 has a $5^{\prime}$ to $3^{\prime}$ exonuclease activity and is an important component of P-bodies of HeLa cells. To find out whether it is also present in P-bodies of hypothalamic neurons, we immunolabeled Dcpla and Xrn1. As expected, Xrn1 colocalized with Dcpla in P-bodies of HeLa cells (Fig. 4D). However, the two proteins showed only a partial colocalization in hypothalamic neurons. In the cell body $70 \%$ ( $\pm 6 \%$ ) of Dcpla foci contained Xrn1, but in dendrites this was the case for only $10 \%( \pm 5 \%)$ of them. In some cells, Xrn1 appeared to be restricted to the cell body (Fig. 4A).

We also tested for the presence of ribosomes in dlP-bodies, using Y10b antibodies that recognize rRNA. Importantly, staining with this antibody was previously found to be the most conclusive tool to document the presence of ribosomes in neuronal granules (Kim et al., 2005). As expected, there was no detectable accumulation of rRNA in Dcpla foci in HeLa cells (Fig. 4C). However, rRNA was present in a fraction of dlP-bodies stained by GW182 antibodies in dendrites of hippocampal neurons (33 $\pm 8 \%$ ) (Fig. $4 B$ ). In the cell body, the diffused intense staining obtained with Y10B antibody made the assessment of colocalization difficult.

The results described above point to major differences in the composition of P-body-like structures between neuronal processes, neuronal cell body, and HeLa cells. A large fraction of dlP-bodies visualized with anti-Dcpla or anti-GW182 antibodies lacks Xrn1 but contains ribosomes, and a fraction of previously described neuronal granules containing ZBP1, FMRP may represent dlP-bodies.

\section{dlP-bodies display directed movements}

To investigate whether dlP-bodies could be involved in transport of mRNAs in dendrites, we assessed whether they were motile by performing video-microscopy of primary hypothalamic neurons expressing GFP-tagged components (Fig. 5 and supplemental Movies 1, 2, 3, available at www.jneurosci.org as supplemental material). Indeed, we found that dlP-bodies labeled with GFPDcp1a or GFP-Ago2 moved with rectilinear trajectories and at constant velocities, indicating a motor-driven movement. During a 5 min observation period, $26.9 \%$ of GFP-Dcpla foci and $38.6 \%$ of Ago 2 foci displayed such movements. Detailed analysis of directed movements (supplemental Fig. S8, available at www. jneurosci.org as supplemental material) revealed that, for GFPDcpla, 9.7\% were retrograde movements, $14.9 \%$ anterograde movements, and $2.3 \%$ bidirectional. Furthermore, dlP-bodies moved an average distance of $5.4 \mu \mathrm{m}(5.5 \mu \mathrm{m}$ for anterograde movement, $5.3 \mu \mathrm{m}$ for retrograde movement), and at an average speed of $0.87 \mu \mathrm{m} / \mathrm{s}(0.75 \mu \mathrm{m} / \mathrm{s}$ for anterograde, and $0.99 \mu \mathrm{m} / \mathrm{s}$ for retrograde). The values were similar for GFP-Dcpla and GFPAgo2, in agreement with their high degree of colocalization in fixed cells. Together, these data suggest that movements of dlPbodies depend on active transport, mediated by molecular motors. Interestingly, this property appears to be specific for neurons

\section{$\leftarrow$}

Figure 2. Localization of miRNAs and their mRNA targets in dIP-bodies. $A, B$, Colocalization of miRNAs and GW182 in dPP-bodies of hypothalamic $(\boldsymbol{A})$ and hippocampal $(\boldsymbol{B})$ neurons. miRNAs let-7 ( $\boldsymbol{A}$ ) or miR-128 (B) were detected by in situ hybridization (top). Staining with anti-GW182 antibody is shown in middle panels. Overlay pictures are shown in bottom, with staining for miRNA in red and for GW182 in green. C, Hypothalamic neurons were cotransfected with plasmids expressing (FP-Ago2 (middle) and a Renilla luciferase (RL) mRNA reporter with three let-7 binding sites in its $3^{\prime}$ UTR (RL-3xB; top). In situ hybridization, using probes complementary to RL mRNA, detected the mRNA (red) in foci that are also positive for CFP-Ag02 (green; bottom). Scale bar, $10 \mu \mathrm{m}$. The insets show $4 \times$ enlargements of indicated areas. DAPI was used for staining the nuclei. 
since P-bodies of HeLa cells did not show obvious directed movements (data not shown).

Because SMN sometimes colocalized with Dcpla in dlP-bodies, we also compared the mobility of SMN to that of Dcpla. As shown in Figure 5, 70.5\% of SMN-RFP granules followed a directed movement during a 5 min observation period. Among them, $29.5 \%$ showed a retrograde movement, $30.8 \%$ an anterograde movement, and $10.26 \%$ a bidirectional movement. Generally, SMN-RFP moved over longer distances $(7.07 \mu \mathrm{m}$ on average $)$ and at a higher velocity $(1.78 \mu \mathrm{m} / \mathrm{s}$ on average) than GFP-Dcpla and GFPAgo2. These findings are in agreement with the observations that most SMN granules are distinct from dlP-bodies.

\section{Synaptic activation relocalizes dlP- bodies to distant dendritic sites}

Having observed the motorized transport of dlP-bodies along dendrites, we wanted to determine whether their localization was modified on synaptic activation. To this end, we measured dendritic distribution of dlP-bodies in hypothalamic neurons that were either untreated or incubated with $30 \mu \mathrm{M}$ NMDA, a glutamate agonist (Fig. 6A,B). Neurons were transfected with GFP-Dcp1a or GFP-Ago2, and we measured in each cell the maximal distance between dlP-bodies and the cell body (Fig. 6C, upper graph). We used a software that measured the exact distances in the cell, taking in account the contour of the cellular processes (see Material and Methods). The results indicated that after 5 min of NMDA treatment, there was no significant change (maximal distance of $72 \pm 9 \mu \mathrm{m}$, compared with $62 \pm 7 \mu \mathrm{m}$ for untreated cells). In contrast, after the 15 min treatment, dlP-bodies were localizing as far as $240 \pm 20 \mu \mathrm{m}$ away from the soma. To obtain a more general view of the localization of dlP-bodies, we then quantified the distribution of GFP-Ago2 positive foci along dendrites, using $50 \mu \mathrm{m}$ slices from the cell body (Fig. 6D). In cells treated with NMDA for $15 \mathrm{~min}$, the distribution of dlPbodies shifted to distal regions: $50 \%$ were distributed 100-250 $\mu \mathrm{m}$ away from the soma, compared with $10 \%$ in control cells. This indicates that dlP-bodies respond to synaptic activation by re-localizing to more distant sites in dendrites.

To better characterize which glutamate receptor was involved in the re- localization of dlP-bodies, we treated cells with different drugs that stimulated either ionotropic (kainate) or metabotropic receptors (DHPG), and we measured the distance from the soma of the most distal granule, as described above. DlP-bodies relocalized to distal ends of the cell after treatment with kainate,

A

E
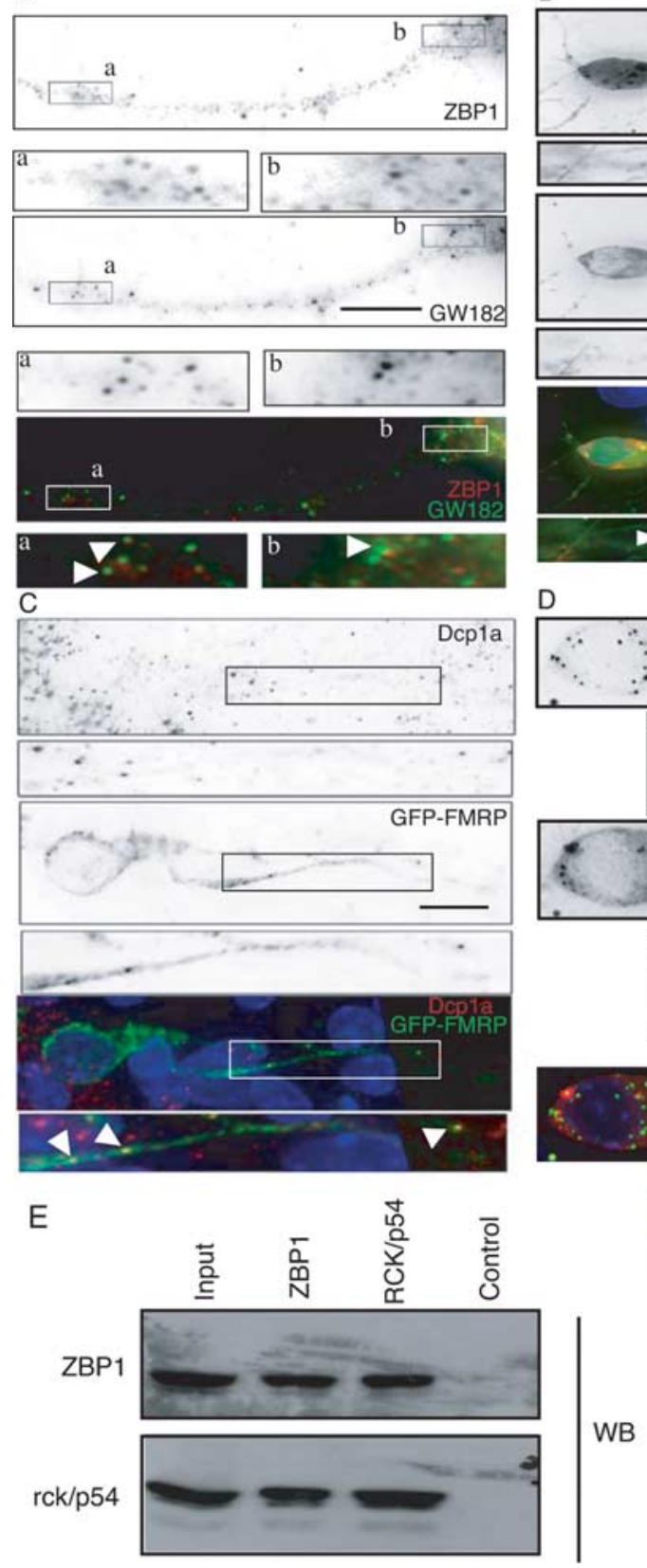

Figure 3. dIP-bodies contain translational repressor proteins. A, Anti-ZBP1 (top) and anti-GW182 (middle) antibody were used for detection of endogenous proteins in hippocampal neurons. On the overlay (bottom) panel, ZBP1 is in red, and GW182 in green. Colocalizations in panel $(\boldsymbol{A}-\boldsymbol{D})$ are marked by arrowheads. Scale bars, $10 \mu \mathrm{m}$. The insets show $4 \times$ enlargements of indicated regions. DAPI was used for staining the nuclei. $\boldsymbol{B}$, Hypothalamic neurons transfected with CFP-Dcp1a (top) and YFP-ZBP1 (middle) show colocalization of (FP and YFP signals in discrete foci. Overlay (lower) panel shows colocalization of CFP-Dcp1 (red) with YFP-ZBP1 (green). C, GFP-tagged FMRP (middle) colocalizes with the endogenous Dcpla (top) in dIP-bodies of hypothalamic neurons transfected with the GFP-FMRP expression plasmid. Overlay (bottom) panel shows colocalization of Dcpla (red) with GFP-FMRP (green). D, Localization of SMN and Dcpla proteins in hypothalamic neurons. Neurons expressing SMN-RFP (middle) were labeled with anti-Dcp1a (top). In overlay panel (bottom) Dcp1a is in green and SMN-RFP in red. E, ZBP1 and RCK/p54 coimmunoprecipitate with each other in protein extracts prepared from purified synaptosomes. Input represents $10 \%$ of the total extract used for each immunoprecipitation reaction. Rabbit polyclonal antibody against GRP78 protein was used in control immunoprecipitation.
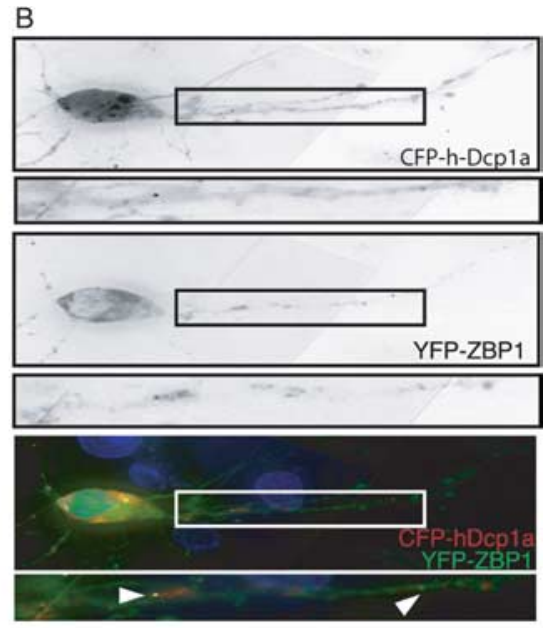

D
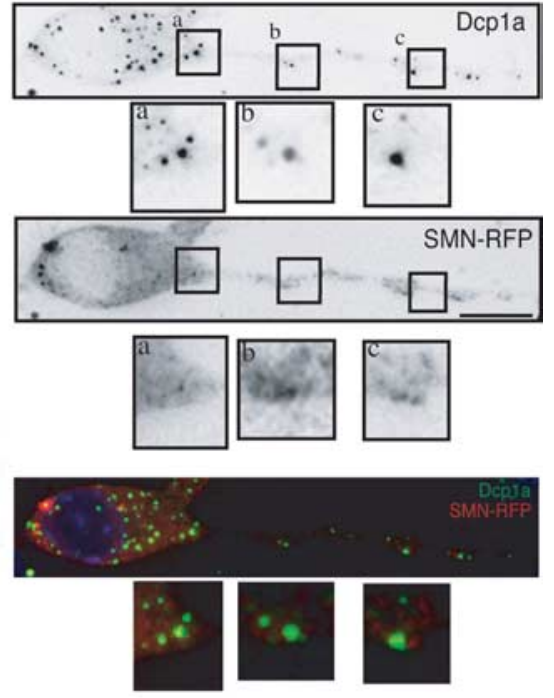

WB

whereas DHPG had little or no effect (Fig. 6E). Furthermore, antagonists of kainate and NMDA, such as DNQX and MK801, blocked the relocalization of dlP-bodies, whereas treatment with MK801 or DNQX alone had no effect. Interestingly, both BDNF and $\mathrm{KCl}$ treatments also caused the relocalization of dlP-bodies to distant sites in dendrites (Fig. 6E). 
A
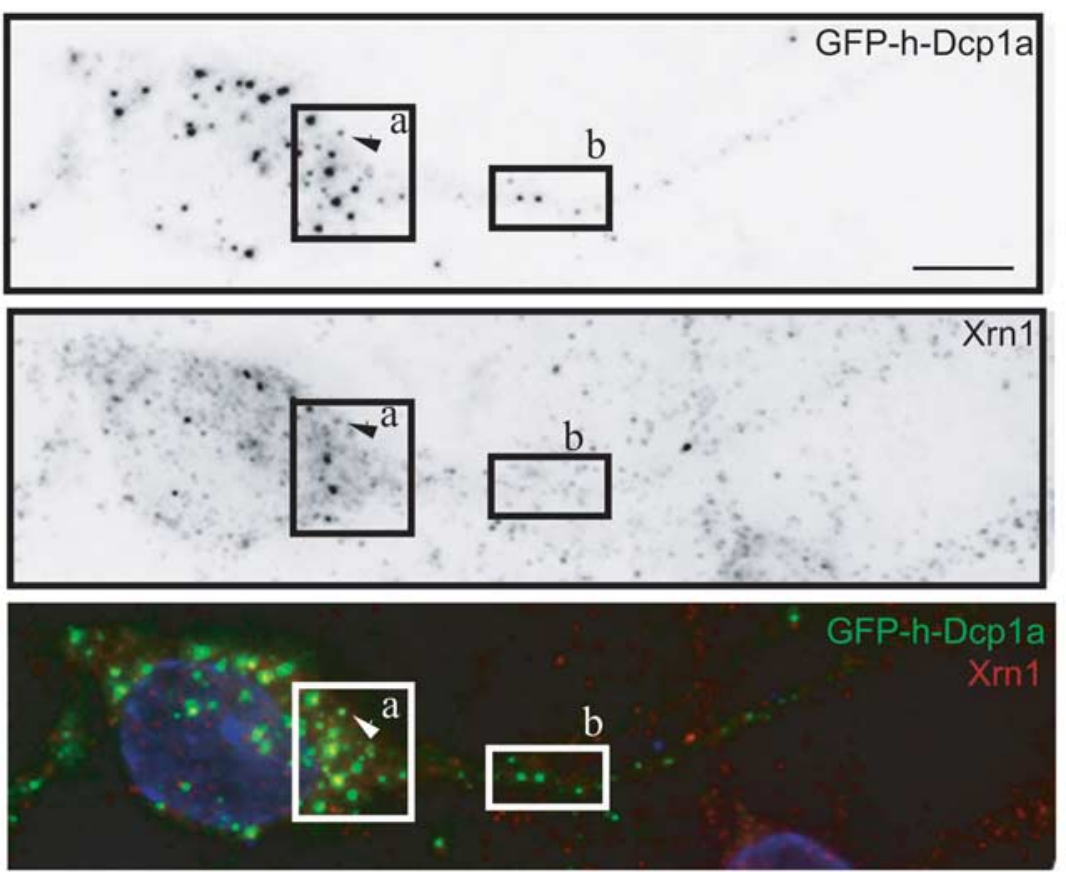

B
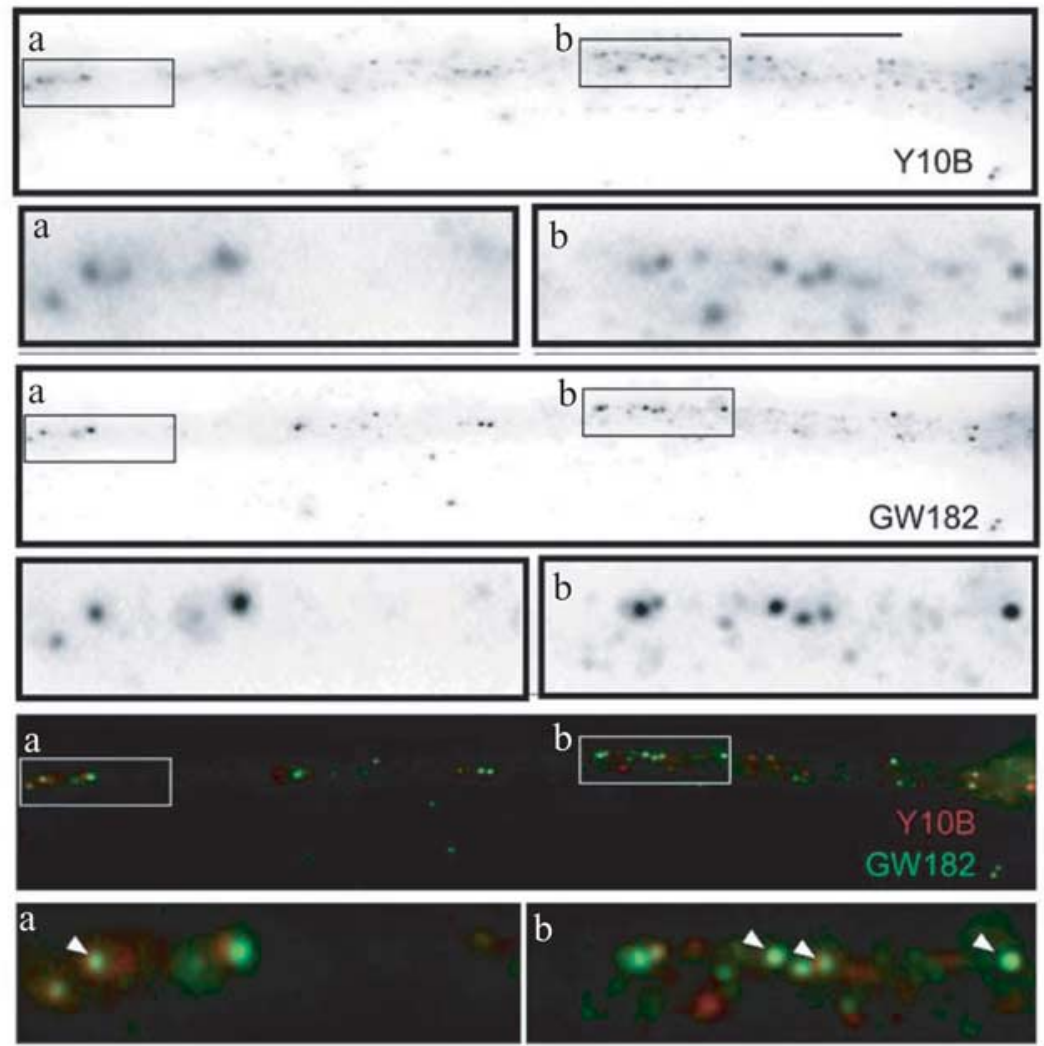

C
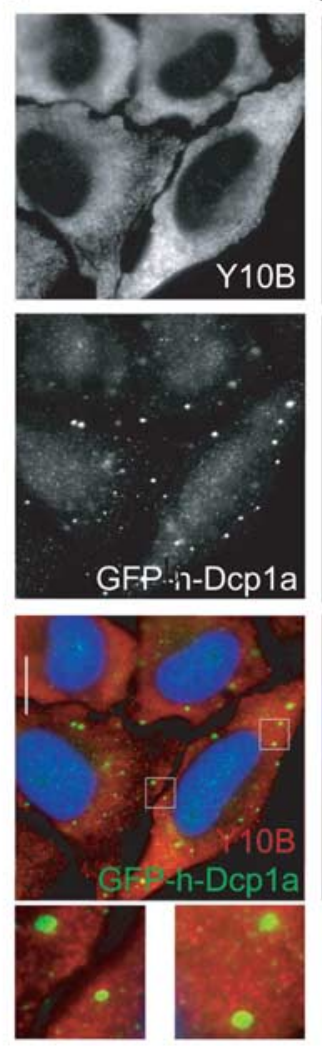

a

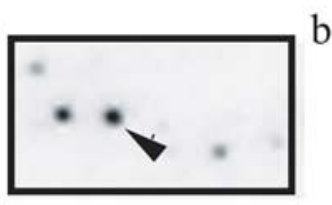

b
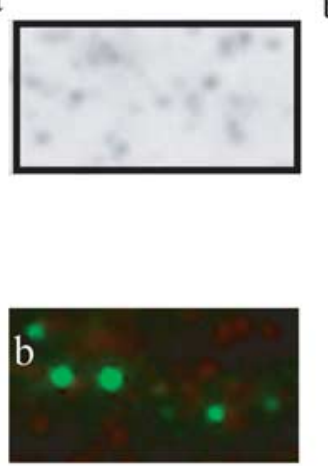

D
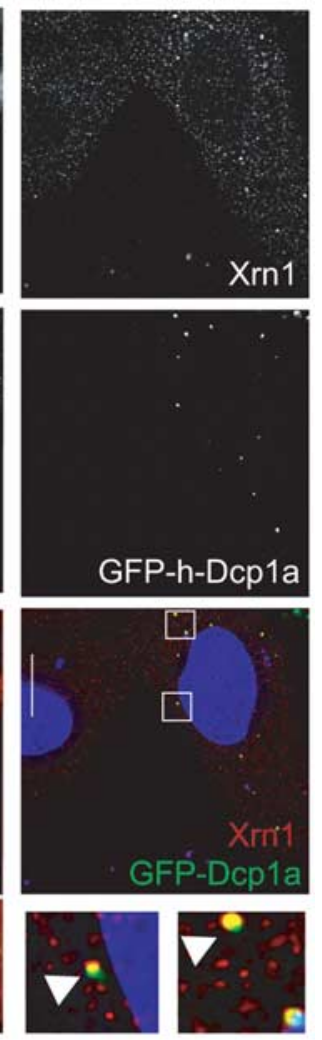

Figure 4. dIP-bodies rarely contain the exonuclease Xrn1, but contain rRNA. A, Localization of Xrn1 (middle panel) and Dcp1a (top) in hypothalamic neurons transfected with a GFP-Dcp1a expression plasmid. The overlay (bottom) shows Xrn1 staining in red, GFP-Dcp1a in green and nuclei, stained with DAPI, in blue. A rabbit anti-Xrn1 antibody was used for detection of endogenous Xrn1. Insets ( $2 \times$ enlargements of the selected areas) show localization of both proteins in soma (left insets) and dendrites (right insets). $\boldsymbol{B}$, Colocalization of rRNA (staining with Y10B mAb in top; red signal in the overlay panel) with anti-GW182 antibodies (middle; green in the overlay) in hippocampal neurons. Insets show $4 \times$ enlargements of the selected areas. $\boldsymbol{C}, \boldsymbol{D}$, Localization of rRNA $(\boldsymbol{C})$ or Xrn1(D) in HeLa cells (top; red in the overlay panel) transfected with GFP-Dcp1a (middle panels; green in the overlay). Nuclei are stained with DAPI (blue in the overlay). Scale bars: $10 \mu \mathrm{m}$ (in $A, B) ; 5 \mu \mathrm{m}$ (in $C, D)$. 

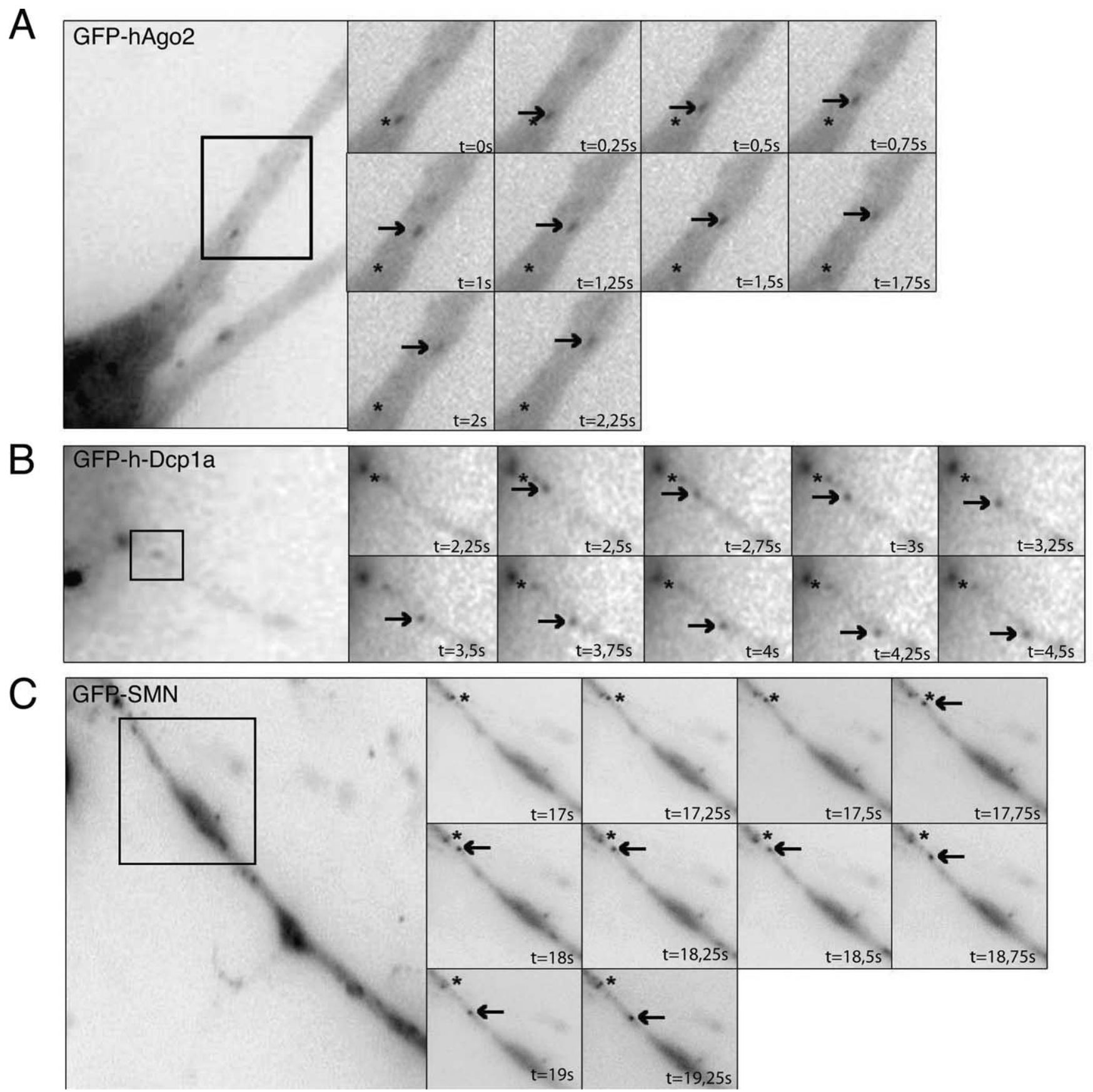

Figure 5. P-body components show directed and motorized movements along dendrites of rat neurons. Hypothalamic neurons transfected with GFP-Ag02 (A), GFP-DCP1a (B) or GFP-SMN (C) were analyzed by time-lapse microscopy. Insets show enlargements ( $5 \times$ for GFPAgo2, $60 \times$ for GFP-Dcp1a, and $11 \times$ for GFP-SMN) of pictures taken at $250 \mathrm{~ms}$ intervals. Asterisks indicate initial position of foci, and arrows indicate their position at the indicated time.

\section{Synaptic activation stimulates the exchange of P-body components}

Although the above experiments analyzed the properties of dlPbodies as a single entity, they provide little information on the rate of exchange of the dlP-body components with the surrounding cytosol. This is however an important point as a storage function would imply long residency times of dlP-body constituents. To address this question, we performed FRAP analysis on GFPDcpla and GFP-Ago2 positive foci, both in dendrites and soma of hypothalamic neurons, and in HeLa cells. Individual bodies were bleached and fluorescence recovery was recorded during at least $15 \mathrm{~min}$. Because dlP-bodies may move during this time, we used a $3 \mathrm{D}$ tracking algorithm that precisely measured the fluorescent signal within the foci (see Material and Methods). As shown in Figure $7 B-D$, GFP-Dcpla was exchanged slowly from foci of hypothalamic neurons, with an immobile fraction of $92 \%$ in the cell body and $90 \%$ in dendrites. GFPAgo 2 had also a large immobile fraction in neurons, of $80 \%$ in both soma and dendrites (Fig. $7 F-H$ ). In HeLa cells, the exchange rate of GFP-Ago2 (Fig. 7E) was similar, with an immobile fraction of $\sim 75 \%$. In contrast, GFP-Dcpla was much more dynamic, as most of the signal was recovered within few minutes, with an immobile fraction of only $20 \%$ after $15 \mathrm{~min}$. Altogether, these data indicate that GFP-Dcpla is stably associated with dlPbodies of hypothalamic neurons, but is rapidly exchanged in P-bodies of HeLa cells.

Because synaptic activation had a strong effect on the localiza- 
A
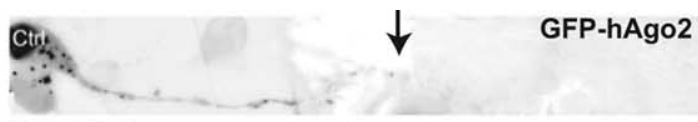

B
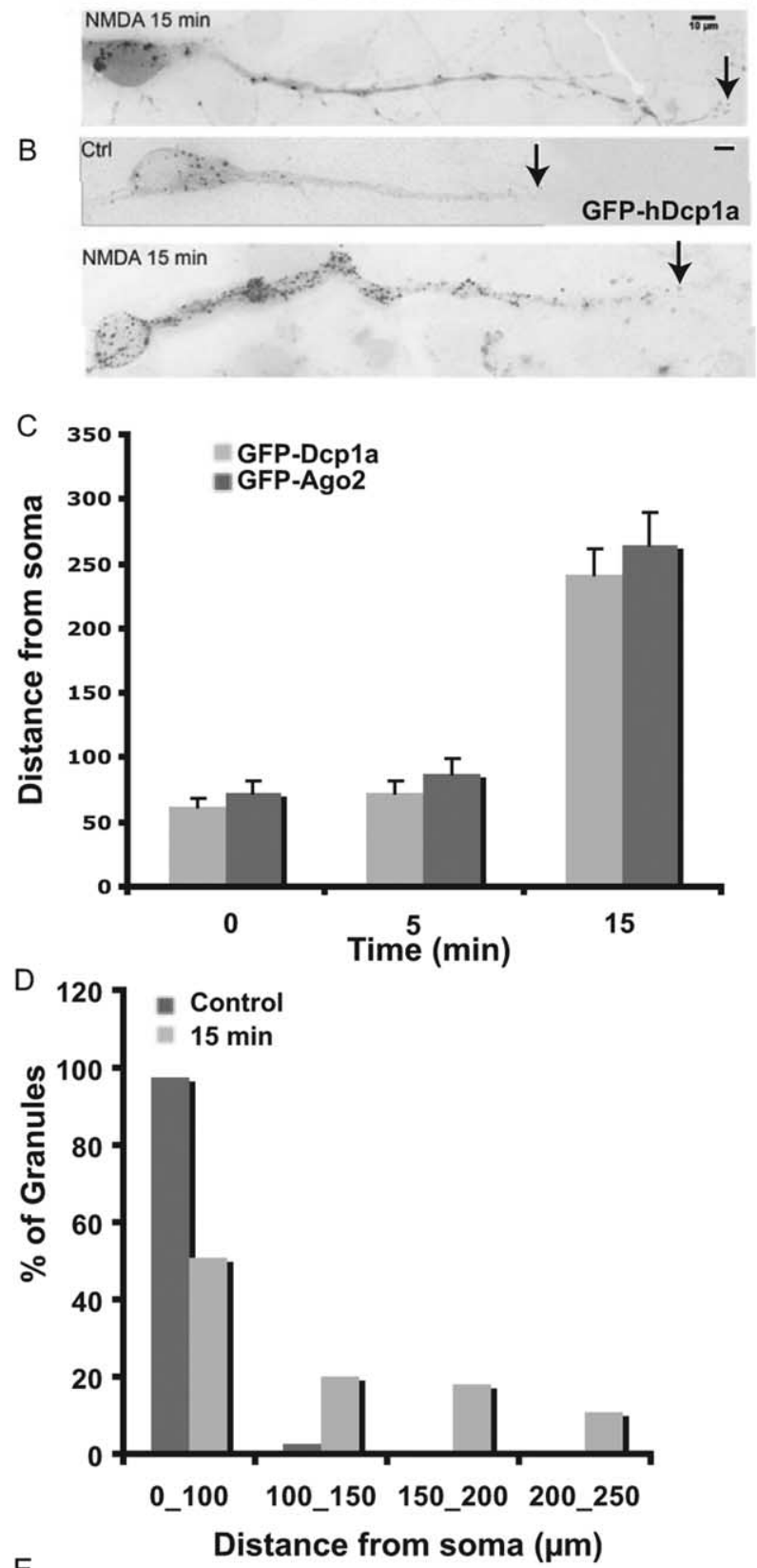

$\mathrm{E}$

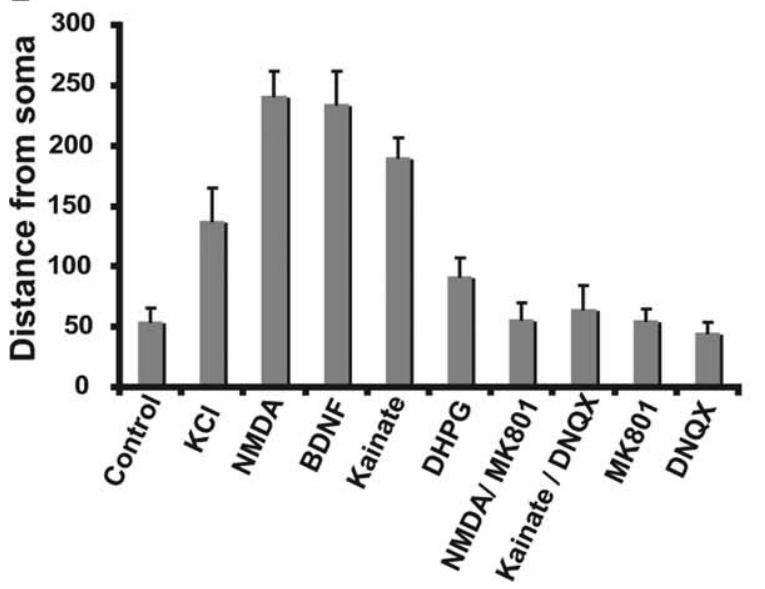

tion of dlP-bodies, it was possible that it could also modify the dynamic properties of their constituents, eventually leading to a modification of their composition. To this end, we repeated the FRAP experiments after synaptic activation. Remarkably, in hypothalamic neurons treated with $30 \mu \mathrm{M}$ NMDA for $15 \mathrm{~min}$, GFPDcpla exchanged quickly from dlP-bodies, with a turn-over rate similar to P-bodies in HeLa cells (Fig. 7G). To test whether the composition of dlP-bodies may be modified during the course of neuronal activation, we performed double-staining experiments using antibodies against endogenous Dcpla and Ago2. Whereas in untreated cells nearly all Dcpla foci contained Ago2 (Figs. 1, $7 \mathrm{H}$ ), the situation had dramatically changed on synaptic activation: approximately half of the Dcpla foci did not stain for Ago2 (56 $\pm 10 \%$ and $45 \pm 6 \%$, after 15 and 60 min of treatment with 30 $\mu \mathrm{M}$ NMDA, respectively) (Fig. $7 J, K)$.

\section{Discussion}

P-bodies have recently emerged as structures implicated in mRNA catabolism and storage, and also in the regulation of mRNA stability and translation by miRNAs (Parker and Sheth, 2007; Pillai et al., 2007). In mammals, most studies have addressed the function of P-bodies in nonpolarized cell lines, with not much attention paid to the role of these structures in neurons, and to their potential relationship to other neuronal granules implicated in transport and storage of mRNAs (Kiebler and Bassell, 2006). In this study, we characterized a novel structure, termed dlP-bodies, which contains many P-body components such as Dcp1a, GW182, and RCK/p54. DlP-bodies are present in the cell body and dendrites of rat hippocampal and hypothalamic neurons, whereas no foci positive for Dcpla were identified in axons.

Unexpectedly, a large fraction of dlP-bodies was also found enriched in ZBP1 and FMRP, two proteins previously implicated in translational repression and transport of mRNAs in neuronal processes. Our results are consistent with a recent report showing that in Drosophila neurons, mRNP granules positive for Staufen and the FMRP-related protein, dFMRP, also contain P-bodies proteins, including homologs of Xrn1, Dcpla, RCK/p54 (Me31B), and an Argonaute protein Ago2. In addition, it was demonstrated that Me31B and TraI function in a complex with dFMRP and regulate dendrite morphogenesis in Drosophila sensory neurons (Barbee et al., 2006). Altogether, these results indicate that at least some mRNP granules present in processes of both mammals and Drosophila neurons may correspond to a specialized class of P-bodies, adapted to neuronal function. Interestingly, the partial colocalization observed for many investigated proteins points toward heterogeneity of neuronal P-bodies and other granules.

Both ZBP1 and FRMP have been implicated in transport of specific mRNAs to synapses (Zhang et al., 2001; De Diego Otero

Figure 6. $A, B$, Treatment with NMDA and other synaptic activators relocates dIP-bodies to distant parts of dendrites of rat neuron. Localization of GFP-Ago2 ( $\boldsymbol{A})$ and GFP-Dcp1a ( $\boldsymbol{B})$ positive foci in hypothalamic neurons either untreated (Ctrl) or after 15 min treatment with $30 \mu \mathrm{M}$ NMDA. C, Quantification of the distance between dIP-bodies and the cell body. GFP-Ago2 (dark gray) and GFP-Dcp1a (light gray) in untreated neurons and in neurons treated with NMDA for 5 or $15 \mathrm{~min}$. The numbers represent the maximum distance from cell soma in which GFP-Ago2 or GFP-DCp1a foci were detectable. D, Distribution of GFP-Ago2 positive foci along dendrites before and after $15 \mathrm{~min}$ NMDA treatment $(n=11)$. $\boldsymbol{E}$, Quantification of dendritic distribution of GFP-Dcp1a after 15 min treatment with different glutamatergic receptor agonists: NMDA (30 $\mu \mathrm{M})$, kainate $(50 \mu \mathrm{m})$ or DHPG $(50 \mu \mathrm{m})$, or BDNF $(50 \mathrm{mg} / \mathrm{ml})$ and KCl $(50 \mathrm{~mm})$. When indicated, specific antagonists of NMDA and kainate, MK-801 $(10 \mu \mathrm{M})$ and DNQX (50 $\mu \mathrm{m})$, respectively, were added to the culture medium. The numbers the maximum distance from cell soma in which GFP-Ago2 or GFP-Dcp1a foci were detectable after different treatments $(n=14)$. 

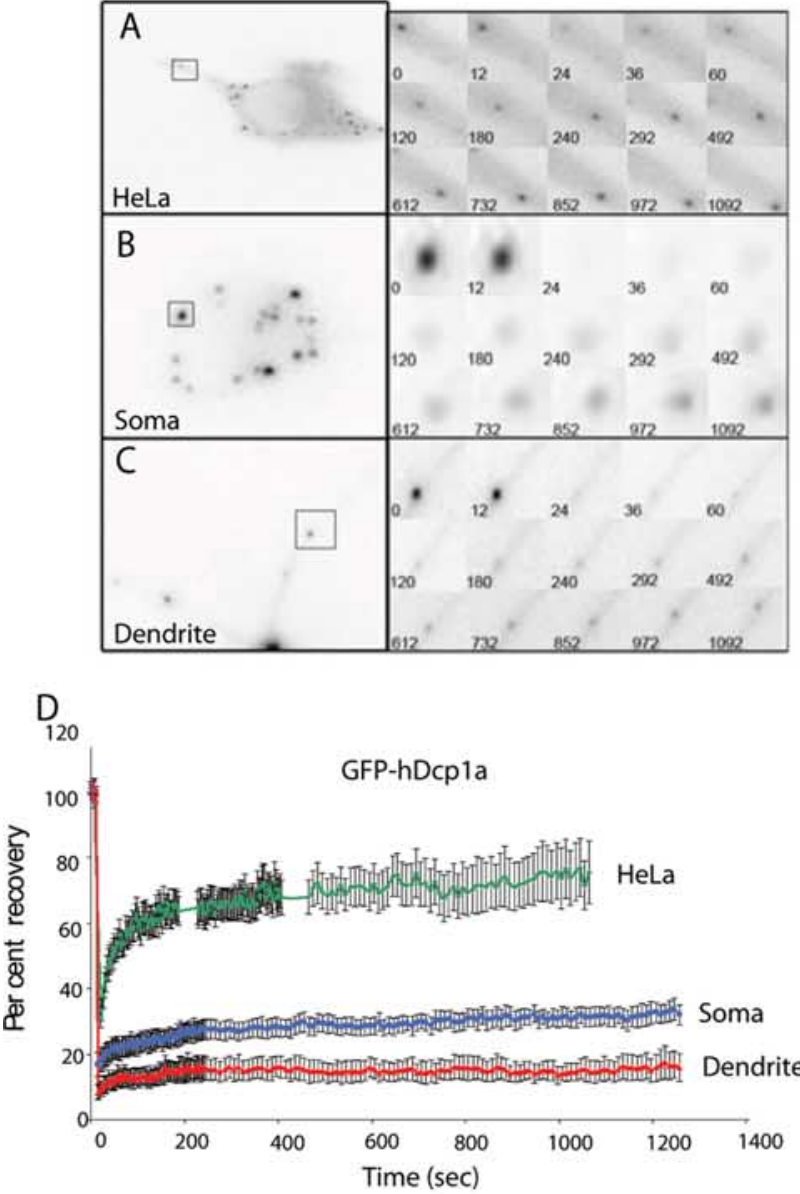

I
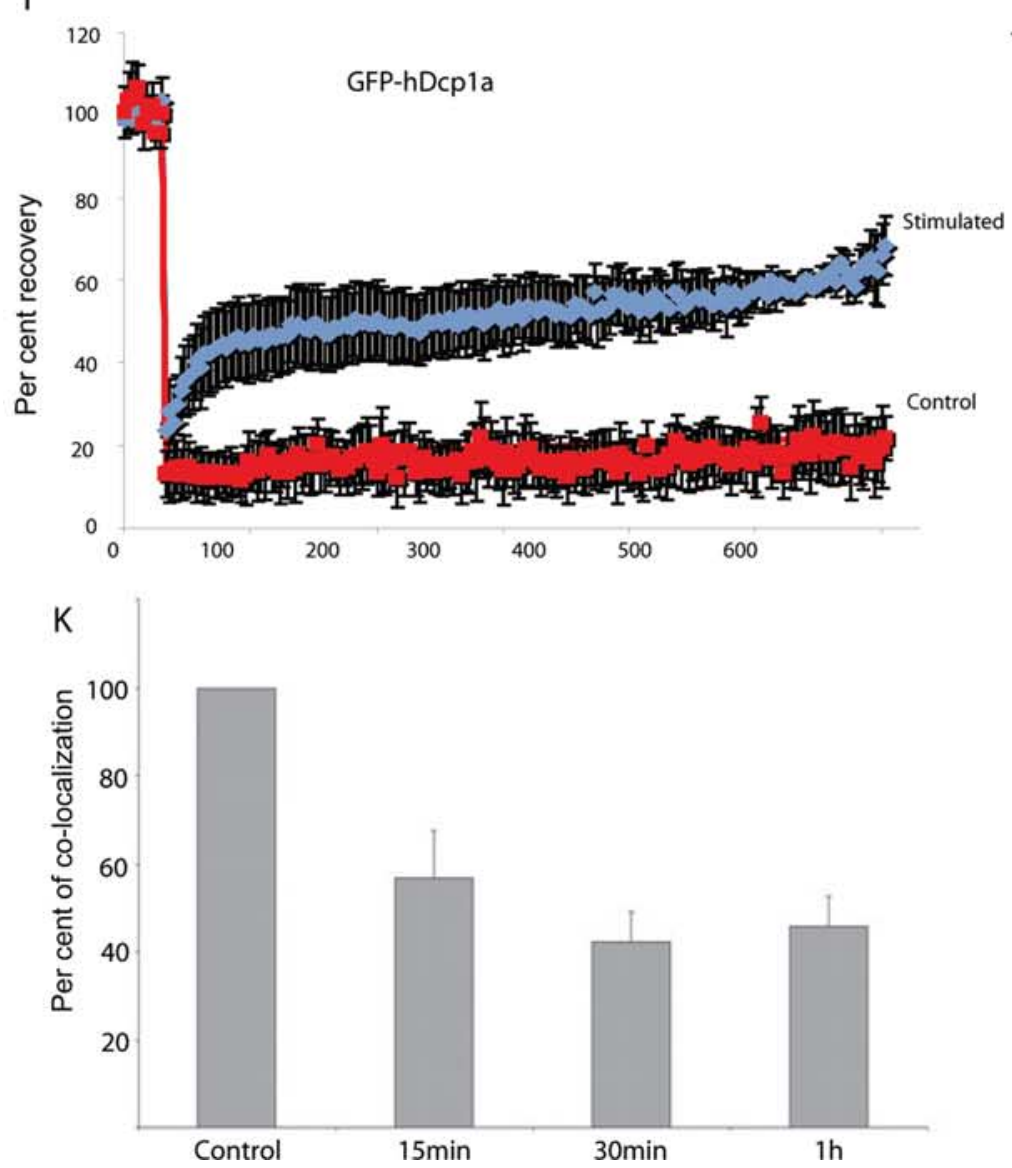

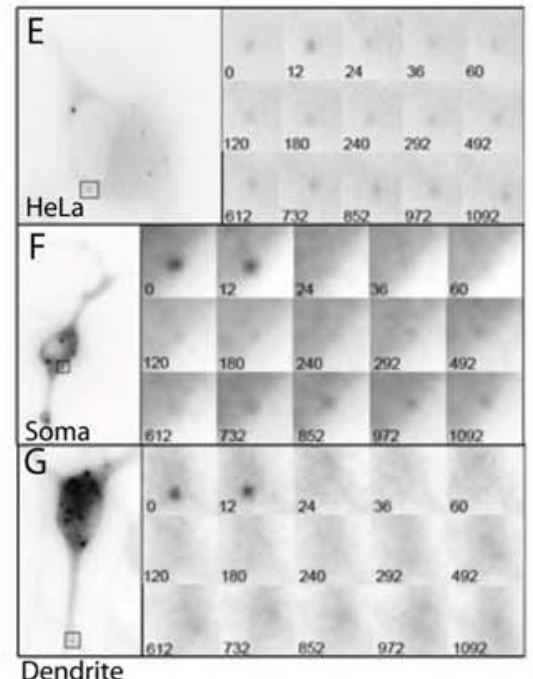

$\mathrm{H}$

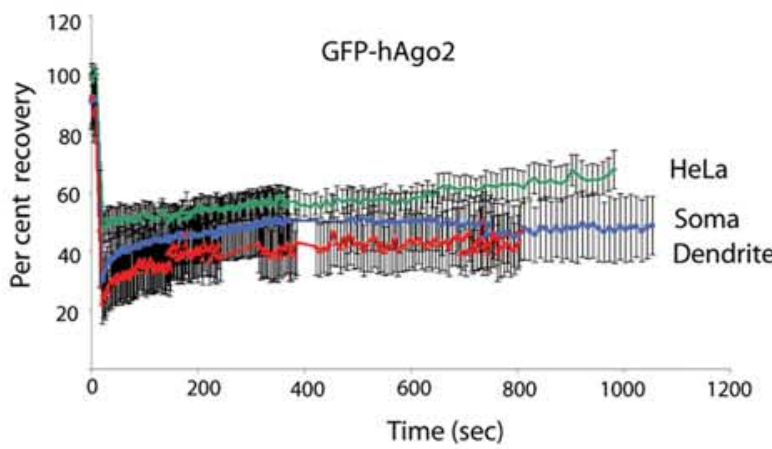

J

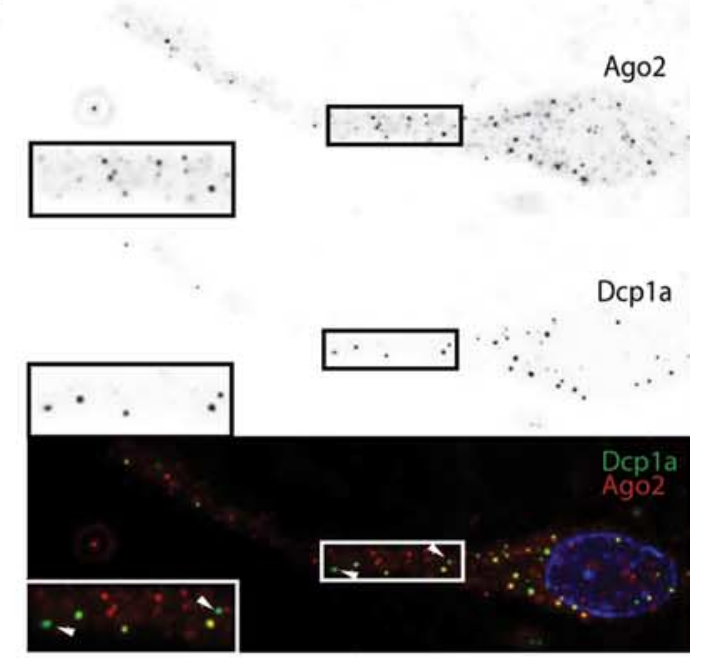


et al., 2002; Tiruchinapalli et al., 2003; Rackham and Brown, 2004; Antar et al., 2005; Zalfa et al., 2006), and our observations that these proteins associate with dlP-bodies suggest that these structures may be involved in mRNA transport. Indeed, we showed by time-lapse microscopy experiments that whereas P-bodies of HeLa cells show random cytoplasmic movements, dendritic dlP-bodies marked with GFP-Dcpla or GFP-Ago2 move bidirectionally along rectilinear trajectories, and at constant velocities. Our data are in agreement with the measurements made for ZBP1 (Tiruchinapalli et al., 2003), which, as shown in our study, is a component of the neuronal dlP-bodies. Similarly, dFMRP has been shown to move bidirectionally with a comparable velocity in Drosophila dendrites (Ling et al., 2004). These observations argue that movements of dlP-bodies in dendrites depend on active transport, mediated by molecular motors. Interestingly, we found that SMN moves over longer distances with a higher velocity. It has been reported that members of dynein and kinesin superfamily of motor proteins show a wide range of velocity (Hirokawa, 1998). Thus, movement of dlPbodies could involve motors which are different from those used by SMN granules and further work will be necessary to identify specific motors involved in transport of these different structures.

In agreement with a role of neuronal dlP-bodies in $\mathrm{mRNP}$ transport, we found that treatment of cultured rat neurons with NMDA re-localized them to more distant sites in dendrites. It has previously been shown that mobility of dendritic ZBP1 granules colocalizing with $\beta$-actin mRNA or ZBP1 alone changes in response to $\mathrm{KCl}$-induced depolarization or NMDA receptor blockage (Tiruchinapalli et al., 2003). However, it is presently unclear whether the increased transport is specifically oriented toward activated synaptic structures or just represents a general enhancement of granule trafficking along the dendrites in response to stimulation. Interestingly, by using different synaptic activators, we observed that dlP-bodies responded to ionotropic glutamate receptors. Moreover, $\mathrm{BDNF}$ and $\mathrm{KCl}$ also induced re-localization of dlP-bodies, suggesting that they respond to a number of different synaptic stimulations.

Many mRNPs are transported in a translationally silent form. We found that most dlP-bodies are deficient for exonuclease Xrn1, but contain rRNA, a ribosomal component, suggesting a primarily storage function of these structures in dendrites, as opposed to a more general catabolic function of P-bodies in the soma. In agreement with this idea, we found in FRAP experiments that even after $15 \mathrm{~min}$, Ago2 remains almost not exchanged from dlP-bodies (immobile fraction of 75-80\%). Most significantly, whereas Dcpla was rapidly exchanged from P-bodies of HeLa cells as previously described (Leung et al., 2006), we found that it turned-over slowly in dlPbodies (immobile fraction of $90 \%$ after $15 \mathrm{~min}$ ). Slow exchange of their components indicates that neuronal dlP-bodies, unlike P-bodies in other cell types, represent stable structures, consistent with the idea that they are involved in $\mathrm{mRNP}$ storage rather than degradation.

\footnotetext{
Figure 7. Synaptic stimulation modifies the exchange rates of of dIP-bodies components and modifies their composition. Hypothalamic neurons and HeLa cells expressing GFP-hDcp1a $(\boldsymbol{A}-\boldsymbol{C})$ or GFP-Ago2 (E-G) were analyzed by FRAP. Specific foci were bleached after $30 \mathrm{~s}$ recording, and fluorescent signals were recorded over time. Images of individual cells and enlargement of the bleached foci is shown. The graphs show recovery curves against time for GFPhDcpla foci (D) or Ago2 foci (H). I, FRAP analysis of GFP-hDcp1 in dendrites before (blue) or after stimulation with $30 \mu \mathrm{M}$ NMDA (red). J, Hypothalamic neurons were stimulated ( $30 \mu \mathrm{M}$ NMDA for $15 \mathrm{~min}$ ), and analyzed by immunofluorescence with antibodies against Ago2 and hDcp1a. $K$, Quantification of the fraction of Dcp1a foci that contained Ago2.
}

Recently, Schratt et al. (2006) have shown that in mammalian neurons the miRNA miR-134 plays a role in translational repression of an mRNA encoding the synapse remodeling protein LIMK1. Treatment of cultured neurons with a neurotrophic factor BDNF resulted in increased translation of LIMK1 mRNA at postsynaptic sites, likely because of the partial relief of the miR-134-mediated repression. It is not known how miR134 and LIMK1 mRNA are transported to distal dendritic sites and what is the mechanism underlying the local translational activation of LIMK1 mRNA. In cultured non-neuronal mammalian cells, miRNAs and their repressed mRNA targets are enriched in P-bodies (Pillai et al., 2007). Importantly, the repressed mRNAs stored in P-bodies can be mobilized to enter active translation in response to different cues, as shown for the CAT-1 mRNA, a target of miR-122, in human hepatoma cells (Bhattacharyya et al., 2006). We show here that dlP-bodies in dendrites contain Ago2, miRNAs and are also enriched in a repressed reporter mRNA, targeted by let-7 miRNA. Furthermore, we found that Dcpla is stably associated to dlP-bodies in unstimulated cell, but exchanges rapidly in and out of dlP-bodies on NMDA treatment. Concomitantly, in our study, the composition of dlPbodies changes, and many of them loose Ago2, suggesting that they release the miRNA repressed mRNPs. In a recent study (Zeitelhofer et al.., 2008), the authors found that hippocampal Dcpla foci are distinct from staufen transport granules, and that they disassemble on synaptic stimulation. Both studies thus suggest that hypothalamic dlPbodies or hippocampal dendritic P-bodies undergo profound modification on synaptic stimulation. These considerations, taken together with other properties of dlP-bodies discussed above, make them excellent candidates for structures participating in transport and local regulation of miRNA targets in dendrites of mammalian neurons.

The cis-acting sequences important for the localization of dendritic mRNAs are commonly found in their 3'UTRs (Martin and Zukin, 2006). However, for many mRNAs, such targeting sequences have not been identified. We found that translational repression induced by miRNA is sufficient to ensure dendritic localization of a reporter mRNA such as RL-3xB, which lacks any apparent dendritic targeting sequence. Possibly, dendritic transport and localization of some endogenous mRNAs depends on their repression by miRNAs (Ashraf and Kunes, 2006; Kosik, 2006; Schuman et al., 2006). However, if this is indeed the case, additional factors would be needed to determine whether the mRNA is recruited to P-bodies remaining in the soma or into P-body-like structures doomed for dendritic transport. Possibly, translational repression by a miRNA in neuronal soma facilitates mRNA recruitment to P-body-like structure for trafficking to dendrites. How mRNAs in dendrites are reactivated for translation is not clear at present. Cytoplasmic polyadenylation element binding $(\mathrm{CPEB})$ protein or neuron specific ELAV proteins are interesting candidates for factors functioning in the activation process. HuR, a constitutively expressed ELAV protein, has been documented to function in the relief of mRNA from the miRNAmediated repression and in promoting mRNA exit from P-bodies in somatic cells (Bhattacharyya et al., 2006). It will be interesting to establish whether neuron-specific ELAV proteins, $\mathrm{HuB}, \mathrm{HuC}$ and $\mathrm{HuD}$, have a similar potential.

\section{References}

Antar LN, Dictenberg JB, Plociniak M, Afroz R, Bassell GJ (2005) Localization of FMRP-associated mRNA granules and requirement of microtubules foractivity-dependent trafficking in hippocampal neurons. Genes Brain Behav 4:350-359.

Ashraf SI, Kunes S (2006) A trace of silence: memory and microRNA at the synapse. Curr Opin Neurobiol 16:535-539.

Bagni C, Mannucci L, Dotti CG, Amaldi F (2000) Chemical stimulation of 
synaptosomes modulates alpha-Ca2+/calmodulin-dependent protein kinase II mRNA association to polysomes. J Neurosci 20:RC76:1-6.

Barbee SA, Estes PS, Cziko AM, Hillebrand J, Luedeman RA, Coller JM, Johnson N, Howlett IC, Geng C, Ueda R, Brand AH, Newbury SF, Wilhelm JE, Levine RB, Nakamura A, Parker R, Ramaswami M (2006) Staufen- and FMRPcontaining neuronal RNPs are structurally and functionally related to somatic P bodies. Neuron 52:997-1009.

Bhattacharyya SN, Habermacher R, Martine U, Closs EI, Filipowicz W (2006) Relief of microRNA-mediated translational repression in human cells subjected to stress. Cell 125:1111-1124.

Boireau S, Maiuri P, Basyuk E, de la Mata M, Knezevich A, Pradet-Balade B, BŠcker V, Kornblihtt A, Marcello A, Bertrand E (2007) The transcriptional cycle of HIV-1 in real-time and live cells. J Cell Biol 179:291-304.

Cougot N, Babajko S, Seraphin B (2004) Cytoplasmic foci are sites of mRNA decay in human cells. J Cell Biol 165:31-40.

De Diego Otero Y, Severijnen LA, van Cappellen G, Schrier M, Oostra B, Willemsen R (2002) Transport of fragile X mental retardation protein via granules in neurites of PC12 cells. Mol Cell biol 22:8332-8341.

Deshler JO, Highett MI, Abramson T, Schnapp BJ (1998) A highly conserved RNA-binding protein for cytoplasmic mRNA localization in vertebrates. Curr Biol 8:489-496.

Eom T, Antar LN, Singer RH, Bassell GJ (2003) Localization of a betaactin messenger ribonucleoprotein complex with zipcode-binding protein modulates the density of dendritic filopodia and filopodial synapses. J Neurosci 23:10433-10444.

Eulalio A, Behm-Ansmant I, Izaurralde E (2007) P bodies: at the crossroads of post-transcriptional pathways. Nat Rev Mol Cell Biol 8:9-22.

Fischer M, Kaech S, Knutti D, Matus A (1998) Rapid actin-based plasticity in dendritic spines. Neuron 20:847-854.

Fuchs E, Flugge G, Czeh B (2006) Remodeling of neuronal networks by stress. Front Biosci 11:2746-2758.

Havin L, Git A, Elisha Z, Oberman F, Yaniv K, Schwartz SP, Standart N, Yisraeli JK (1998) RNA-binding protein conserved in both microtubule- and microfilament-based RNA localization. Genes Dev 12:1593-1598.

Hirokawa N (1998) Kinesin and dynein superfamily proteins and the mechanism of organelle transport. Science 279:519-526.

Hirokawa N (2006) mRNA transport in dendrites: RNA granules, motors, and tracks. J Neurosci 26:7139-7142.

Kiebler MA, Bassell GJ (2006) Neuronal RNA granules: movers and makers. Neuron 51:685-690.

Kim HK, Kim YB, Kim EG, Schuman E (2005) Measurement of dendritic mRNA transport using ribosomal markers. Biochem Biophys Res Commun 328:895-900.

Kindler S, Wang H, Richter D, Tiedge H (2005) RNA transport and local control of translation. Annu Rev Cell Dev Biol 21:223-245.

Klann E, Dever TE (2004) Biochemical mechanisms for translational regulation in synaptic plasticity. Nature Rev 5:931-942.

Kosik KS (2006) The neuronal microRNA system. Nat Rev 7:911-920.

Krichevsky AM, Kosik KS (2001) Neuronal RNA granules: a link between RNA localization and stimulation-dependent translation. Neuron 32:683-696.

Krichevsky AM, King KS, Donahue CP, Khrapko K, Kosik KS (2003) A microRNA array reveals extensive regulation of microRNAs during brain development. RNA 9:1274-1281.

Lagos-Quintana M, Rauhut R, Yalcin A, Meyer J, Lendeckel W, Tuschl T (2002) Identification of tissue-specific microRNAs from mouse. Curr Biol 12:735-739.

Leung AK, Calabrese JM, Sharp PA (2006) Quantitative analysis of Argonaute protein reveals microRNA-dependent localization to stress granules. Proc Natl Acad Sci U S A 103:18125-18130.

Ling SC, Fahrner PS, Greenough WT, Gelfand VI (2004) Transport of Drosophila fragile $\mathrm{X}$ mental retardation protein-containing ribonucleopro- tein granules by kinesin-1 and cytoplasmic dynein. Proc Natl Acad Sci U S A 101:17428-17433.

Liu J, Valencia-Sanchez MA, Hannon GJ, Parker R (2005) MicroRNAdependent localization of targeted mRNAs to mammalian P-bodies. Nat Cell Biol 7:719-723.

Martin KC, Zukin RS (2006) RNA trafficking and local protein synthesis in dendrites: an overview. J Neurosci 26:7131-7134.

Meijering E, Jacob M, Sarria JC, Steiner P, Hirling H, Unser M (2004) Design and validation of a tool for neurite tracing and analysis in fluorescence microscopy images. Cytometry A 58:167-176.

Parker R, Sheth U (2007) P bodies and the control of mRNA translation and degradation. Mol Cell 25:635-646.

Pillai RS, Bhattacharyya SN, Artus CG, Zoller T, Cougot N, Basyuk E, Bertrand E, Filipowicz W (2005) Inhibition of translational initiation by Let-7 MicroRNA in human cells. Science 309:1573-1576.

Pillai RS, Bhattacharyya SN, Filipowicz W (2007) Repression of protein synthesis by miRNAs: how many mechanisms? Trends Cell Biol 17:118-126.

Rackham O, Brown CM (2004) Visualization of RNA-protein interactions in living cells: FMRP and IMP1 interact on mRNAs. EMBO J 23:3346-3355.

Rage F, Riteau B, Alonso G, Tapia-Arancibia L (1999) Brain-derived neurotrophic factor and neurotrophin-3 enhance somatostatin gene expression through alikely direct effect on hypothalamic somatostatin neurons. Endocrinology 140:909-916.

Ross AF, Oleynikov Y, Kislauskis EH, Taneja KL, Singer RH (1997) Characterization of a beta-actin mRNA zipcode-binding protein. Mol Cell Biol 17:2158-2165.

Scarborough DE, Scarborough DE, Lee SL, Dinarello CA, Reichlin S (1989) Interleukin-1 beta stimulates somatostatin biosynthesis in primary cultures of fetal rat brain. Endocrinology 124:549-551.

Schratt GM, Tuebing F, Nigh EA, Kane CG, Sabatini ME, Kiebler M, Greenberg ME (2006) A brain-specific microRNA regulates dendritic spine development. Nature 439:283-289.

Schuman EM, Dynes JL, Steward O (2006) Synaptic regulation of translation of dendritic mRNAs. J Neurosci 26:7143-7146.

Smirnova L, Grafe A, Seiler A, Schumacher S, Nitsch R, Wulczyn FG (2005) Regulation of miRNA expression during neural cell specification. Eur J Neurosci 21:1469-1477.

Sutton MA, Schuman EM (2006) Dendritic protein synthesis, synaptic plasticity, and memory. Cell 127:49-58.

Tiruchinapalli DM, Oleynikov Y, Kelic S, Shenoy SM, Hartley A, Stanton PK, Singer RH, Bassell GJ (2003) Activity-dependent trafficking and dynamic localization of zipcode binding protein 1 and beta-actin mRNA in dendrites and spines of hippocampal neurons. J Neurosci 23:3251-3261.

Twiss JL, van Minnen J (2006) New insights into neuronal regeneration: the role of axonal protein synthesis in pathfinding and axonal extension. J Neurotrauma 23:295-308.

van Dijk E, Cougot N, Meyer S, Babajko S, Wahle E, Seraphin B (2002) Human Dcp2: a catalytically active mRNA decapping enzyme located in specific cytoplasmic structures. EMBO J 21:6915-6924.

Xia Z, Dudek H, Miranti CK, Greenberg ME (1996) Calcium influx via the NMDA receptor induces immediate early gene transcription by a MAP kinase/ERKdependent mechanism. J Neurosci 16:5425-5436.

Zalfa F, Achsel T, Bagni C (2006) mRNPs, polysomes or granules: FMRP in neuronal protein synthesis. Curr Opin Neurobiol 16:265-269.

Zeitelhofer M, Karra D, Macchi P, Tolino M, Thomas S, Schwarz M, Kiebler M, Dahm R (2008) Dynamic interaction between P-bodies and transport ribonucleoprotein particles in dendrites of mature hippocampal neurons. J Neurosci 28:7555-7562.

Zhang HL, Eom T, Oleynikov Y, Shenoy SM, Liebelt DA, Dictenberg JB, Singer RH, Bassell GJ (2001) Neurotrophin-induced transport of a betaactin mRNP complex increases beta-actin levels and stimulates growth cone motility. Neuron 31:261-275. 